\title{
Hydromechanical Investigations on the Self-propping Potential of Fractures in Tight Sandstones
}

\author{
Chaojie Cheng ${ }^{1,2}$ (1) $\cdot$ Harald Milsch $^{1}$ (1)
}

Received: 27 July 2020 / Accepted: 30 April 2021 / Published online: 21 May 2021

(c) The Author(s) 2021

\begin{abstract}
The hydromechanical properties of single self-propping fractures under stress are of fundamental interest for fracturedrock hydrology and a large number of geotechnical applications. This experimental study investigates fracture closure and hydraulic aperture changes of displaced tensile fractures, aligned tensile fractures, and saw-cut fractures for two types of sandstone (i.e., Flechtinger and Fontainebleau) with contrasting mechanical properties, cycling confining pressure between 5 and $30 \mathrm{MPa}$. Emphasis is placed on how surface roughness, fracture wall offset, and the mechanical properties of the contact asperities affect the self-propping potential of these fractures under normal stress. A relative fracture wall displacement can significantly increase fracture aperture and hydraulic conductivity, but the degree of increase strongly depends on the fracture surface roughness. For smooth fractures, surface roughness remains scale-independent as long as the fracture area is larger than a roll-off wavelength and thus any further displacement does not affect fracture aperture. For rough tensile fractures, these are self-affine over a larger scale so that an incremental fracture wall offset likely leads to an increase in fracture aperture. X-ray microtomography of the fractures indicates that the contact area ratio of the tensile fractures after the confining pressure cycle inversely correlates with the fracture wall offset yielding values in the range of about 3-25\%, depending, first, on the respective surface roughness and, second, on the strength of the asperities in contact. Moreover, the contact asperities mainly occur isolated and tend to be preferentially oriented in the direction perpendicular to the fracture wall displacement which, in turn, may induce flow anisotropy. This, overall, implies that relatively harder sedimentary rocks have a higher self-propping potential for sustainable fluid flow through fractures in comparison to relatively soft rocks when specific conditions regarding surface roughness and fracture wall offset are met.
\end{abstract}

Keywords Self-propping fracture $\cdot$ Mechanical aperture $\cdot$ Hydraulic aperture $\cdot$ Normal stress $\cdot$ Fracture wall offset $\cdot$ Surface roughness

\section{Introduction}

Sufficient amounts of fluid need to be circulated through rock masses in the upper crust at depths as deep as $4-5 \mathrm{~km}$ for an economic utilization of reservoirs, e.g., as enhanced geothermal systems (Blöcher et al. 2016; Kushnir et al. 2018) or for unconventional oil and gas extraction. Fractures, predominantly controlling fluid flow in low permeable rocks, are crucial in this regard. Consequently, the

Chaojie Cheng

chaojie@gfz-potsdam.de

1 Helmholtz Centre Potsdam, GFZ German Research Centre for Geosciences, Potsdam, Germany

2 Institute for Geosciences, University of Potsdam, Potsdam, Germany hydromechanical properties of rock fractures have received attention in numerous studies in the past (e.g., Bandis et al. 1983; Raven and Gale 1985; Zimmerman and Bodvarsson 1996; Sausse 2002; Konzuk and Kueper 2004; Rutqvist 2015). The property of single self-propping fractures under normal stresses is the one of the most fundamental problems in fractured-rock hydrology and is the starting point to understand more complex systems, e.g., shear fractures or fracture networks. To quantitatively characterize fluid flow through a single rock fracture, which is deformable under normal stresses, the notions of mechanical and hydraulic aperture are commonly considered (Witherspoon et al. 1980; Barton et al. 1985; Zimmerman et al. 1992). The mechanical aperture is the arithmetic mean of the separation distance between the opposing fracture surfaces, while the hydraulic aperture represents the equivalent flow through a fracture 
idealized as two smooth, parallel plates applying the socalled "cubic law" (Zimmerman and Bodvarsson 1996).

Numerous experimental studies on the hydromechanical properties of single fractures have previously been performed, generally considering a lithostatic load equivalent to 1-3 km crustal depth (23 MPa/km) (Bandis et al. 1983; Hofmann et al. 2016; Milsch et al. 2016; Vogler et al. 2016; Crawford et al. 2017) but in some cases down to $7 \mathrm{~km}$ depth (Kranzz et al. 1979; Durham and Bonner 1994). Experimentally it showed, that a mismatched joint in granitic rocks remains hydraulically conductive under normal stresses up to $160 \mathrm{MPa}$ (Durham and Bonner 1994). Moreover, fractures in granite and granodiorite are hard to completely close, either mechanically or hydraulically, under purely normal stresses (Hofmann et al. 2016; Vogler et al. 2016) unless the fracture surfaces are mated and/or subjected to extremely high loads (Kranzz et al. 1979; Durham and Bonner 1994). In addition, studies on fractures in other rock types, such as slate, sandstone, dolerite, and limestone, essentially yielded similar results (Bandis et al. 1983; Crawford et al. 2017), which permit to conclude that the permeability of mismatched fractures is more sustainable in comparison to aligned fractures at the same normal stress conditions.

In the past, valuable insights into the mechanisms of stress-dependent hydromechanical properties of self-propping fractures were obtained. The main factors that control fracture deformation and fluid flow are the surface roughness (Bandis et al. 1983), fracture wall offset or shear displacement (Plouraboué et al. 1995; Vogler et al. 2016; Fang et al. 2018; Kluge et al. 2021), number of loading-unloading cycles (Brown and Scholz 1985; Hofmann et al. 2016; Milsch et al. 2016), fracture size (Raven and Gale 1985), direction of fluid flow relative to the fracture wall displacement (Thompson and Brown 1991; Auradou et al. 2005; Watanabe et al. 2008; Nemoto et al. 2009; Lang et al. 2018), and fracture types, i.e., either natural or artificially generated (Kling et al. 2016; Vogler et al. 2016). The main conclusions drawn from these previous studies can be summarized as follows: (1) the irreversible deformation (permeability decline) after each loading-unloading cycle reduces with the number of cycles. Generally, 3-4 full cycles can efficiently eliminate any inelastic deformation component. (2) The degree of fracture closure strongly depends on the fracture surface topography as well as on the elastic properties of the material. (3) Artificially displaced fractures show shear dilation due to the mismatch between the surfaces. (4) The larger the relative fracture wall displacement, the less is the stress-dependent permeability reduction and anisotropy. (5) A shear fracture under normal stress shows shear dilation with gouge production and permeability variations depending on fracture surface properties. (6) A permeability reduction is more pronounced when the flow direction is oriented in parallel to the fracture wall displacement. (7) Flow channelling and tortuosity increase with increasing normal stress. (8) The contact area ratio, defined as the ratio between the contact area of the asperities and the nominal fracture area nonlinearly varies with aperture closure. Overall, the intrinsic rock properties, e.g., the fracture surface roughness and its mechanical behavior, fundamentally determine the properties mentioned before.

Previously, most experimental studies were performed on igneous rocks. However, for enhanced geothermal systems (Blöcher et al. 2016) or unconventional oil and gas exploitation, the fracture behavior in low permeability formations consisting of sedimentary rock such as tight sandstones, siltstones, and shales is of paramount interest. In this context, hydraulic fracturing is crucial for increasing the transmissivity of the formations (Blöcher et al. 2016; Zimmermann et al. 2018; Hofmann et al. 2019). Here, the generated fractures are tensile or shear fractures, depending on the stress field. Hydraulic fractures, generally, propagate in the direction perpendicular to the minimum principal stress (Zhuang et al. 2020). However, for sedimentary formations containing bedding layers or other anisotropic structural features, the fracture plane orientation will be strongly affected by the present structure-stress correlation encountered in situ (Cosgrove 1995; Huang and Liu 2017). In addition, fracture surfaces generated in sedimentary rocks show different spatial correlations (e.g., the Hurst exponent $H$ is about 0.5 for tensile fractures in sandstone) compared to the ones in igneous rocks (e.g., $H \approx 0.8$ for fractures in granite and basalt) (Boffa and Allain 1998; Ponson et al. 2007; Schmittbuhl et al. 2008). Other features (e.g., bedding layers, grain sizes) in sedimentary rocks may also affect fracture surface roughness. Consequently, it is necessary to investigate the self-propping potential of sedimentary rock fractures with different features to conclude whether these fractures are sustainable, thus allowing for sufficient fluid flow under stress. This information will then help to decide whether proppants should be used in such reservoirs or not.

In summary, the fracture surface roughness, the degree of geometric matching of the opposing fracture surfaces, and the mechanical properties of the fracture are the key factors that determine fracture deformation and fluid flow. In this study, sedimentary rocks, i.e., two types of sandstone are investigated regarding the mechanical and hydraulic response of different fracture configurations on effective pressure cycles. A softer, more compressible rock is compared to a stronger one, as are tensile fractures with different degrees of displacement and saw-cut fractures. This study emphasizes how the key factors mentioned before affect fracture aperture, both mechanically and hydraulically, when the normal stress on the fracture plane is varied and, moreover, what the correlation between the aperture distribution, the fracture wall offset, and the contact area ratio is. Comprehensive flow-through experiments and drained 
compression tests were conducted and complemented with microstructural investigations by fracture surface scans as well as X-ray microtomography $(\mu \mathrm{CT})$.

\section{Rock Samples and Methodology}

\subsection{Sample Preparation and Experimental Apparatus}

In this study, two types of sandstone were selected for hydromechanical experiments to examine the characteristics of single fracture flow subject to normal stress cycles. The two rock types were Flechtinger sandstone, quarried from an outcrop of the Lower Permian (Upper Rotliegend) near Flechtingen, Germany and Fontainebleau sandstone, quarried near Fontainebleau, France. The geology, petrophysics, and mechanical properties of both rocks are well known (Fischer et al. 2012; Saadi et al. 2017) and have been intensively investigated (Zang et al. 1996; Hassanzadegan et al. 2012, 2013; Schepers and Milsch 2013). Fontainebleau sandstone is an almost monomineralic sandstone ( $>99.5$ wt $\%$ quartz), while Flechtinger sandstone is composed of quartz (63 wt \%), K-feldspar (14 wt \%), albite (12 wt \%), illite (7 wt $\%)$, calcite ( $2 \mathrm{wt} \%$ ), and hematite ( $1 \mathrm{wt} \%$ ) as determined by X-ray diffraction (XRD). Figure 1 shows optical micrographs of the two rock types, where the Fontainebleau sandstone possesses a relatively uniform grain size in comparison to Flechtinger sandstone. The average grain size of both rocks is in the same order of magnitude, i.e., $200 \mu \mathrm{m}$ for Fontainebleau sandstone and $125 \mu \mathrm{m}$ for Flechtinger sandstone as derived from 2-D image analyses.

The basic physical parameters of the two rock types display significant differences, as shown in Table 1. These sandstones represent relatively "soft" (Flechtinger sandstone) and "hard" rock (Fontainebleau sandstone), respectively.
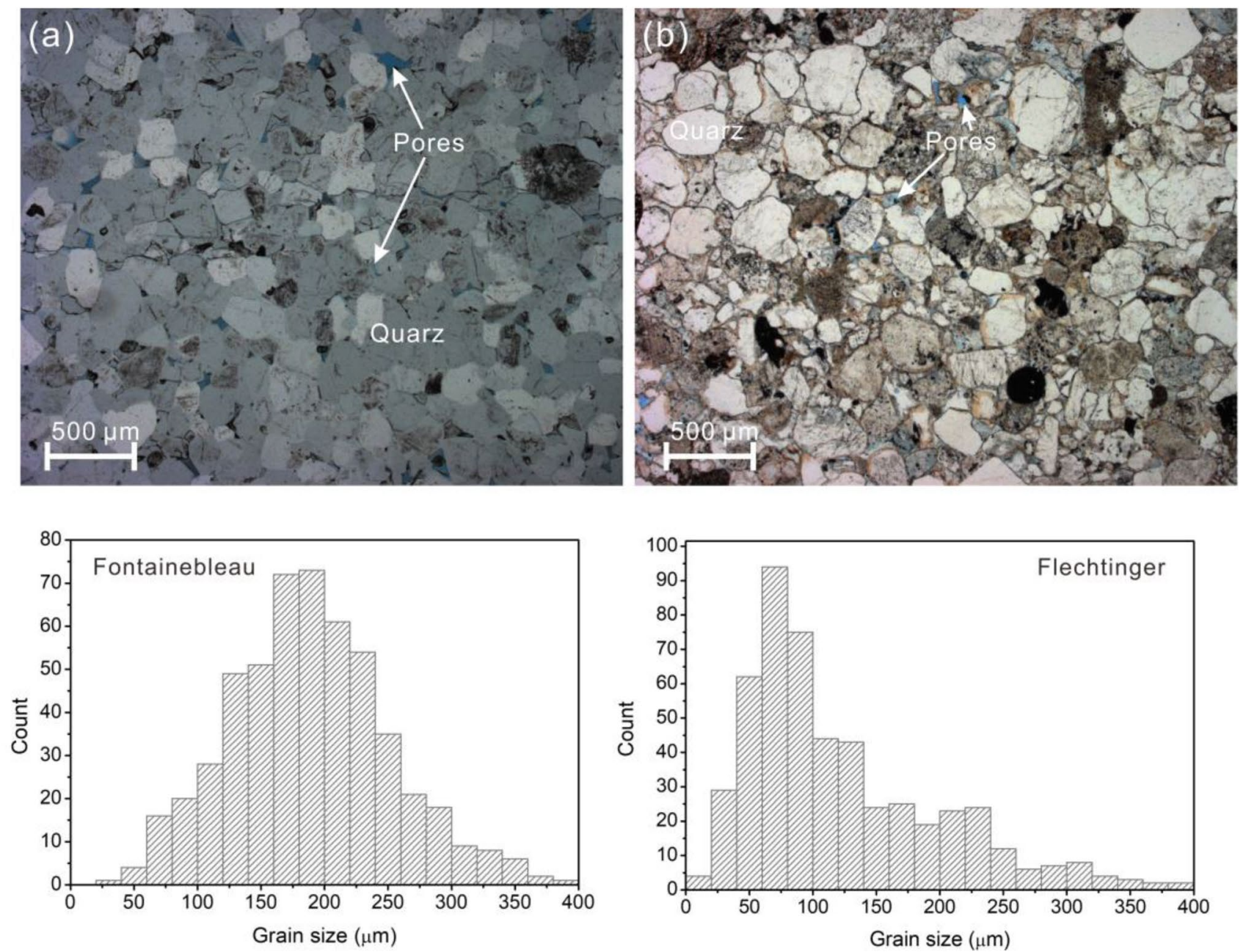

Fig. 1 Optical micrographs and grain size distributions derived from 2-D image analyses using ImageJ (Schneider et al. 2012). a Fontainebleau sandstone and b Flechtinger sandstone 
Table 1 Basic physical parameters of the two rock types

\begin{tabular}{llllll}
\hline Rock type & $\phi(\%)$ & $\rho\left(\mathrm{g} / \mathrm{cm}^{3}\right)$ & $k\left(\mathrm{~m}^{2}\right)$ & $\mathrm{UCS}(\mathrm{MPa})$ & $K_{\mathrm{b}}(\mathrm{GPa})$ \\
\hline Flechtinger & 8.1 & 2.40 & $10^{-17}-10^{-18}$ & $56.7-100$ & 15.9 \\
$\begin{array}{l}\text { Fontaineb- } \\
\text { leau }\end{array}$ & 2.5 & 2.56 & $10^{-18}$ & 122.3 & 33.0 \\
\hline
\end{tabular}

Notes: $\phi$ is porosity measured by saturation and weighing and $\rho$ is the bulk density. The uniaxial compressive strength (UCS) and the drained bulk modulus $\left(K_{\mathrm{b}}\right)$ of Flechtinger sandstone were taken from previous investigations (Hassanzadegan et al. 2012). Flechtinger sandstone is anisotropic, where the UCS parallel and perpendicular to the bedding layers shows different values of up to $100 \mathrm{MPa}$ (Zang et al. 1996). The permeability $k$ of Flechtinger sandstone was measured with the flow direction oriented perpendicular to the bedding. UCS and $K_{\mathrm{b}}$ of Fontainebleau sandstone with a porosity of $\sim 4 \%$ are reported in Baud et al. (2014) and Arns et al. (2002), respectively. One can infer that the present Fontainebleau sandstone having a porosity lower than $4 \%$ is mechanically stronger, implying that the values reported in the table for UCS and $K_{b}$ should be considered lower bounds

However, both sandstone types used in this study are of low matrix permeability in the order of $10^{-18} \mathrm{~m}^{2}$, as determined with a gas permeameter.

The Fontainebleau sandstone used in this study appears isotropic and homogeneous. The Flechtinger sandstone is relatively homogeneous but microscopically shows bedding layers. The mechanical properties, consequently, vary in dependence of the stress orientation relative to bedding (Zang et al. 1996). In addition, generated fractures along the bedding layers may significantly differ in roughness depending on whether the layers consist of finer or coarser grains. To minimize any influence of bedding on the fracture roughness and the permeability measurements, all sample cores were drilled from larger blocks perpendicular to bedding. Three cylindrical samples of each rock type (Flechtinger sandstone: FF1, FF2, and FF3; Fontainebleau sandstone: FOF1, FOF2, and FOF3) with a diameter of $30 \mathrm{~mm}$ and a length of $40 \mathrm{~mm}$ were prepared. The six samples were split into two halves using a Brazilian test setup (Fig. 2a) at a displacement rate of $2 \times 10^{-6} \mathrm{~m} / \mathrm{s}$, yielding negligible edge damage. In addition, a rock block was cut using a saw and the obtained halves were then tightly attached. Subsequently, cylindrical core samples were drilled along the fracture located in the core center. Thin section images (Fig. 16) of the generated fractures indicate that sawing results in intragranular fracturing while tensile fractures mainly form along the grain boundaries in Flechtinger sandstone as well as both across grains and along grain boundaries in Fontainebleau sandstone.

Examples of separated sample halves are displayed in Fig. 2b. The respective subsamples were labelled A and B. The sample halves were subsequently assembled with or without PEEK spacers on the top and the bottom ends to create a fixed displacement with offsets of $0.2 \mathrm{~mm}$ (FF2 and
FOF2) (Fig. 2e) and $0.75 \mathrm{~mm}$ (FF1 and FOF1) (Fig. 2f). FF3 and FOF3 were aligned without pre-displacement (Fig. 2d), and saw-cut samples (FF4 and FOF4) were obtained (Fig. 2c). All samples were then assembled with two plugs that connect to the pore fluid system of the flow-through apparatus. A heat-shrink tubing jackets the sample to isolate the pore fluid system from the confining pressure fluid (silicone oil) and a thin metal sheet placed between the fracture gap and the jacket was introduced to minimize any risk of jacket punching at elevated confining pressure conditions.

A flow-through apparatus comprising a hydrostatic pressure vessel was used in this study (Milsch et al. 2008). The specimen assembly was mounted in the vessel and connected to the pore fluid system, which comprises an upstream and a downstream syringe pump (ISCO 260D). The hydrostatic confining pressure is generated with silicone oil using another syringe pump (ISCO 65D). During a flow-through experiment, the downstream pump was maintained in constant pressure mode with the upstream pump providing a constant fluid flow rate. The flow direction during a test is from the bottom to the top of the sample. The differential pore pressure between the sample ends is monitoring by a differential pressure transducer (IPD 40, ICS Schneider Messtechnik) with a range of $0-0.6 \mathrm{MPa}$ and an accuracy of $<0.2 \%$.

\subsection{Experimental Procedures}

\subsubsection{Determination of Hydraulic Aperture}

The assembled samples were vacuum-saturated with deionized water before the experiment. After the installation, under an initial confining pressure $p_{\mathrm{c}}$ of $2 \mathrm{MPa}$, water was continuously flown through the entire pore fluid system, keeping the downstream side open to the atmosphere, until the system was free of air as evidenced by the absence of air bubbles in the effluent. The pore pressure $p_{\mathrm{p}}$ was then increased to $1 \mathrm{MPa}$ and maintained constant throughout the experiment. The confining pressure was further increased to $5 \mathrm{MPa}$ as the starting point of a loading-unloading cycle [ $5 \leftrightarrow 30 \mathrm{MPa}$ for all samples except FF1 $(10 \leftrightarrow 35 \mathrm{MPa})$ ]. During the experiment, the confining pressure was increased or decreased stepwise with a regular interval of $5 \mathrm{MPa}$, and the sample permeability was measured at each pressure level.

The linear Darcy's law is commonly used to describe fluid flow through porous media (Darcy 1856),

$Q=\frac{k A}{\mu L} \Delta P$

where $Q$ is the flow rate, $\Delta P$ is the differential pressure over the sample length $L, \mu$ is the dynamic fluid viscosity, $A$ is the 
(a)

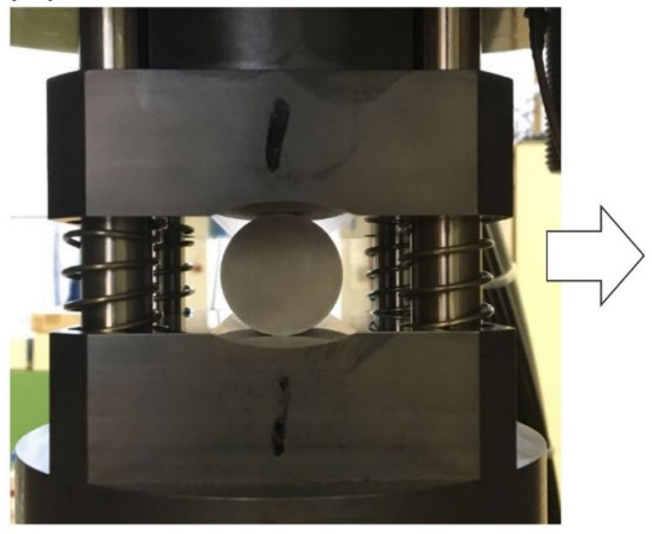

(c)

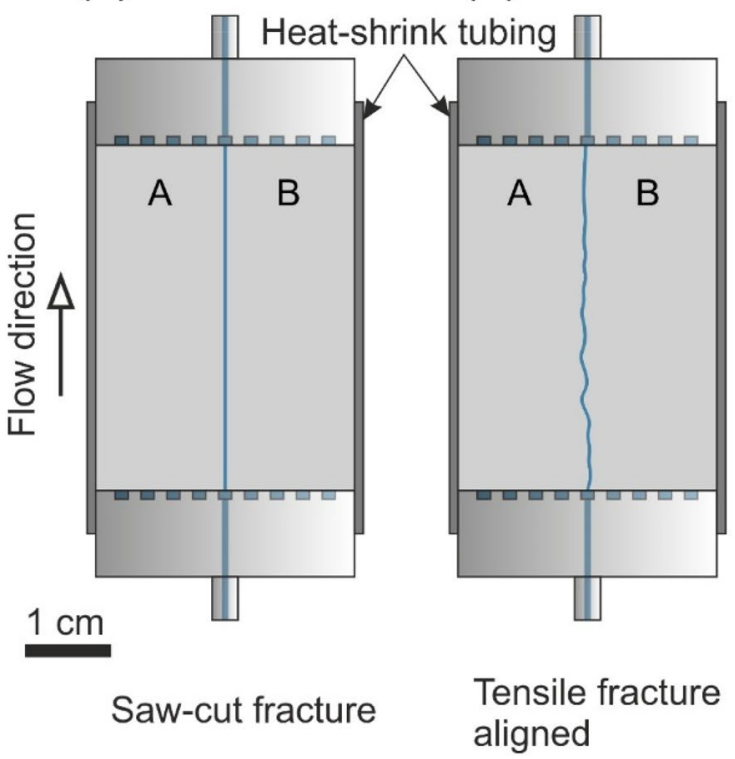

Fig. 2 Preparation of the fractured samples. a Tensile fracture generated by a Brazilian test setup; b representative fractured Fontainebleau sandstone (white) and Flechtinger sandstone (red) cores; schematic illustrations of the assembled specimens, with $\mathbf{c}$ aligned

cross-section area of the sample, and $k$ is its intrinsic permeability. For fluid flow through a single rock fracture, one commonly idealizes the fluid to flow through two smooth, parallel fracture plates. With the assumptions that Darcy's law is valid and that the flow of an incompressible Newtonian fluid is laminar, the so-called "cubic law" is derived by applying the parallel-plate model (Zimmerman and Bodvarsson 1996),

$Q=\frac{b_{\mathrm{h}}^{3} W}{12 \mu L} \Delta P$, (b)

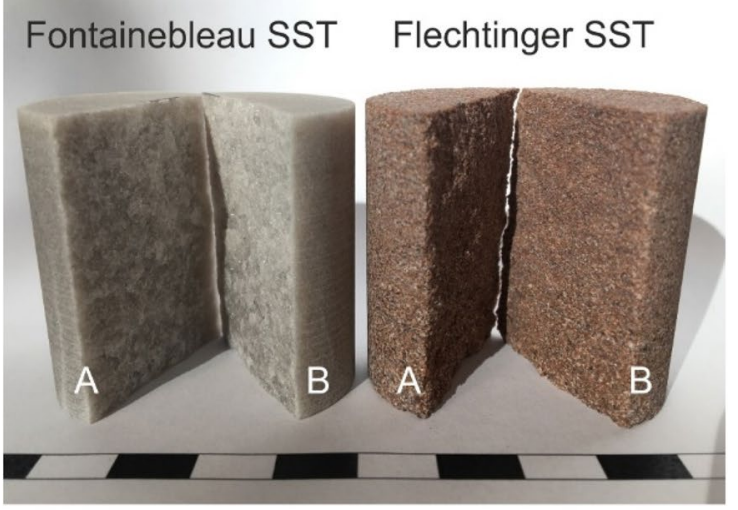

(e)

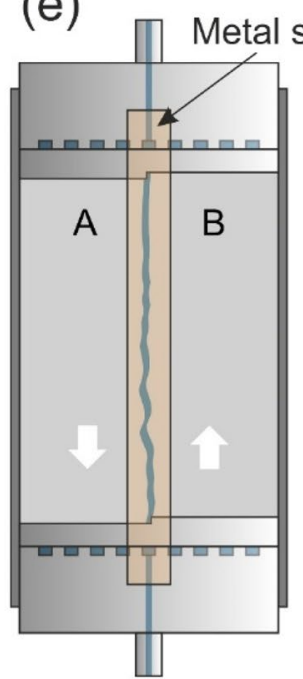

Tensile fracture Offset: $0.2 \mathrm{~mm}$ $(\mathrm{f})$

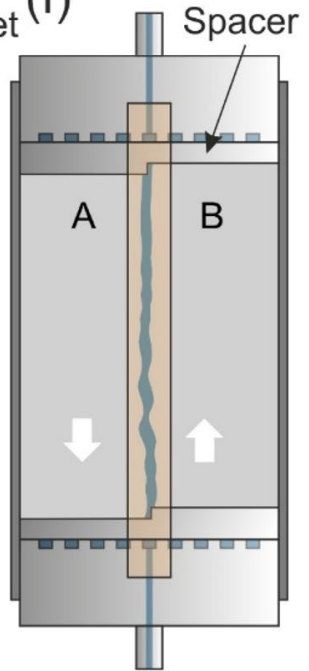

Tensile fracture Offset: $0.75 \mathrm{~mm}$

saw-cut sample core, $\mathbf{d}$ aligned tensile fracture, e mismatched tensile fracture with an offset of $0.2 \mathrm{~mm}$, and $\mathbf{f}$ mismatched tensile fracture with an offset of $0.75 \mathrm{~mm}$

where $W$ is the width of the fracture, and $b_{\mathrm{h}}$ is the separation distance between the two smooth, adjacent fracture plates. In rough fractures, however, the latter parameter is considered as an equivalent aperture, called the hydraulic aperture. Based on the "cubic law", the fracture permeability $k_{\mathrm{f}}$ can then be expressed as (Witherspoon et al. 1980),

$k_{\mathrm{f}}=\frac{b_{\mathrm{h}}^{2}}{12}$.

Although the present sandstone samples are fractured porous media, the fracture permeability is orders of 
magnitude higher than the matrix permeability, which, consequently, is considered to be negligible. In this study, the equivalent hydraulic aperture $b_{\mathrm{h}}$ was calculated for the principal purpose to compare its value to the mechanical aperture (i.e., the geometric separation distance between the two fracture surfaces).

\subsubsection{Determination of Mechanical Aperture Changes}

There are several direct and indirect methods of measuring mechanical aperture changes during loading-unloading operations. Bandis et al. (1983) measured the total vertical deformation of a fractured sample in a uniaxial compression device, where the fracture is placed perpendicular to the normal stress. By subtracting the corresponding deformation of the solid rock without a fracture (obtained from separate measurements on intact samples), fracture aperture deformation was determined. Raven and Gale (1985) performed a direct measurement of the axial deformation of a circular fracture in a cylindrical sample core with three linear variable differential transformers (LVDT) evenly distributed around the sample and oriented in parallel to the longitudinal axis. Vogler et al. (2016) measured the volume changes of the confining pressure fluid during loading-unloading cycles. An additional test on an intact sample was conducted as a reference to calibrate the effects of compression of the rubber jacket and the confining pressure fluid. In addition, Hofmann et al. (2016) measured the axial and lateral strain of a sample, where a single fracture was in parallel to the sample axis, using two axial extensometers and one circumferential chain extensometer in a triaxial experimental setup. Fracture aperture deformation was indirectly determined by subtracting the elastic axial strain from the total lateral strain.

In this study, the pore pressure was maintained constant at $1 \mathrm{MPa}$ throughout the experiment, and the total volume changes $\Delta V$ of the pore fluid were monitored with the downstream pump during the loading-unloading cycles. The mechanical aperture changes $\Delta b_{\mathrm{m}}$ can then be expressed as,

$\Delta b_{\mathrm{m}}=\frac{\Delta V-\Delta V_{\text {pore }}}{W L}$,

where $\Delta V_{\text {pore }}$ is the corresponding pore volume change of the rock matrix. For Flechtinger sandstone samples, $\Delta V_{\text {pore }}$ was obtained from previous loading and unloading cycles on intact samples of the same rock at hydrostatic stress conditions (Hassanzadegan et al. 2012, 2013). The only calibration parameter, here, is the sample bulk volume. For Fontainebleau sandstone samples, due to the low matrix permeability $\left(\sim 1 \times 10^{-18} \mathrm{~m}^{2}\right)$, the low porosity $(\sim 2.5 \%)$, and the short experimental duration of each loading/unloading interval (5 MPa; about $4 \mathrm{~min}$ ), $\Delta V_{\text {pore }}$ for this rock type is assumed negligible.

The total volume changes during initial loading can be attributed to both fracture and pore volume changes and may also result from an adjustment of the specimen assembly, e.g., the closure of small gaps between individual assembly parts. Therefore, in the following, only those results are compared that were obtained at confining pressures between 5 and $30 \mathrm{MPa}$.

In addition to directly measuring mechanical aperture changes, a complementary analysis was performed using the fracture surface topographies obtained from white light interferometry (Sect. 2.3).

\subsection{Fracture Surface Topography}

\subsubsection{Fracture Surface Measurements and Roughness Determination}

The methods applied to measure the topography of solid surfaces, including contacting and non-contacting methods, evolved with technological progress and a concurrent increase in efficiency: from early studies using profilometry (Bandis et al. 1983), image analysis of polished cross-sections perpendicular to the fracture (Hakami and Larsson 1996), laser scanning (Neuville et al. 2012; Singh et al. 2015), photogrammetric scans (Vogler et al. 2016, 2018), X-ray computed microtomography ( $\mu$ CT) (Renard et al. 2009; Diaz et al. 2017), to white light interferometry (Renard et al. 2012; Zou et al. 2019). In this study, the fracture surface topographies of samples FF2, FF3, FF4, FOF2, FOF3, and FOF4 were measured before the experiments using white light interferometry (Keyence VR $3000)$. The resolution of the horizontal $x-y$ coordinates is $23.518 \mu \mathrm{m}$ and the vertical resolution is $1.0 \mu \mathrm{m}$, which yields approximately 2 million data points for each surface.

Numerous parameters have been defined to characterize surface roughness (Li and Zhang 2015), such as the joint roughness coefficient (JRC) (Barton 1973), which is an empirical parameter obtained by comparing fracture profiles to standards, developed further with the introduction of statistical parameters (Tse and Cruden 1979). In this study, we apply statistical expressions to directly analyze the scanned 3-D surface data, i.e., the peak asperity height $R_{\mathrm{p}}$, the average roughness $R_{\mathrm{m}}$, and the root-mean-square roughness $R_{\mathrm{rms}}$,

$R_{\mathrm{p}}=\max \left|z_{\mathrm{i}}-z_{\mathrm{a}}\right|$,

$R_{\mathrm{m}}=\frac{1}{n} \sum_{\mathrm{i}=1}^{n}\left|z_{\mathrm{i}}-z_{\mathrm{a}}\right|$, 
$R_{\mathrm{rms}}=\sqrt{\frac{1}{n} \sum_{\mathrm{i}=1}^{n}\left(z_{\mathrm{i}}-z_{\mathrm{a}}\right)^{2}}$,

where $z_{\mathrm{i}}$ is the height of the $i$ th point and $z_{\mathrm{a}}$ is the mean height of the elevation plane, which is discretized by $n$ points. The global statistical parameters provide a direct comparison between samples, helping to distinguish the different surface topographies quantitatively.

In addition, rock interfaces (e.g., faults, natural fractures, and artificial fractures) are commonly classified as self-affine structures over a large range of length scales (Candela et al. 2012), which are used to numerically generate fractures for simulations (Schmittbuhl et al. 2008; Lang et al. 2015, 2016). In such simulations, it is assumed that the fracture surface remains invariant under the transformation:

$\Delta x \rightarrow \lambda \Delta x, \Delta y \rightarrow \lambda \Delta y, \Delta z \rightarrow \lambda^{H} \Delta z$,

where $\lambda$ is the wavelength and $H$ is the Hurst exponent (Persson et al. 2004; Schmittbuhl et al. 2004), indicating a selfaffine behavior if $H$ is between 0 and $1 . H$ can be estimated based on the 1-D Fourier power spectrum,

$C(q) \propto q^{-1-2 H}$,

where $q=2 \pi / \lambda$ is the wavevector varying between $2 \pi / l$ and $2 \pi / a$, and $l$ is the observed length, and $a$ is the smallest wavelength, i.e., $23.518 \mu \mathrm{m}$. In this study, the 1-D power spectrum of the profile $z\left(x, y_{0}\right)$ along the sample length is analyzed, where $x$ indicates the direction parallel to the displacement. The intrinsic spatial correlation behavior of the surface fluctuations along the displacement can thus be derived.

\subsubsection{Mechanical Aperture Calculations}

Since the fracture surfaces are not identical between samples it is difficult to quantitatively analyze whether the permeability changes are related to parameter differences (i.e., the displacements) or the intrinsic properties of the fracture surfaces. Thus, further numerical investigations were performed based on the surface topography measurements to obtain correlations between the mechanical aperture and surface roughness, surface displacement, as well as contact area ratio. Mechanical aperture can be determined by measuring the upper, and the lower fracture walls relative to a reference plane (Hakami and Larsson 1996) or by measuring the separation distances oriented perpendicular to the local trend of the fracture walls (Mourzenko et al. 1995; Ge 1997). Both methods yield very similar results (Konzuk and Kueper 2004). In this study, the former definition of mechanical aperture was used by applying a best-fitting plane. The mean mechanical aperture $b_{\mathrm{m}}$ can then be expressed as,
$b_{\mathrm{m}}=\frac{1}{A_{\mathrm{f}}} \int \Delta z(x, y) \mathrm{d} A$,

where $A_{\mathrm{f}}=W(L-\delta)$ is the nominal fracture area of the adjacent fracture surfaces, with $\delta$ being the displacement along the sample length, and $\Delta z(x, y)$ is the height difference between the adjacent points on the upper and the lower fracture surfaces.

For the saw-cut samples FF4 and FOF4, the two surfaces of the halves were used for the calculation. For tensile fractures, the initial matching of the aligned halves is difficult since the data obtained for the adjacent fracture surfaces cannot be exactly related, the datum plane of each scan may be not identical, and the initial contact area is hard to estimate. To simplify the dynamic adjustment (e.g., movement or rotation) of two surface topographies, duplicate fracture surfaces were used (i.e., the surfaces A and B are identical to one set of the fracture surface data). Therefore, the fracture aperture at aligned conditions, theoretically, is equal to zero when applying this method. In practice, due to the loss of some grains on the fracture surfaces after separation, the two opposite surfaces do not perfectly match. Furthermore, the tensile fractures generated by the Brazilian test method may display a slightly concave surface geometry resulting from damage transfer during splitting since the fracture edges are subject to compression and the maximum tensile stress and strain occur about $5 \mathrm{~mm}$ away from the load contact ( $\mathrm{Li}$ and Wong 2013). Consequently, the tensile fractures display a slightly larger contact area along the fracture edges compared the interior of the fracture surfaces. However, this feature was found to be more obvious in Flechtinger sandstone than in Fontainebleau sandstone (see Sect. 3.4 and Fig. 11).

Figure $3 \mathrm{a}$ illustrates the procedure of fracture displacement, where the lower surface $A$ is fixed, and the upper surface B is allowed to move along the sample length corresponding to specimen $\mathrm{B}$ of the true sample. The contact area is maintained at a minimum but $>3$ contact points, and any rotation due to the surface adjustment is omitted. In this way, one obtains the correlation between the initial mechanical aperture and the displacement of each fracture surface.

Fracture deformation resulting from normal stresses has been extensively studied by applying purely elastic, elastoplastic, and interpenetration contact models ( $\mathrm{Li}$ et al. 2015; Kling et al. 2018; Zou et al. 2019). The interpenetration model is a rather simple analytical model yielding fairly good agreement with the results of fluid flow measurements (Watanabe et al. 2008; Nemoto et al. 2009). In this model, the two fracture surfaces are displaced relative to each other, where the overlapping parts of the asperities $\left(\Delta z_{i}<0\right)$ are removed and their distance is taken as zero (i.e., contacting asperities). Kling et al. (2018) compared the three models and found that the interpenetration model yields the largest contact area. It should be noted that this model is 
(a) Upper and lower fracture surfaces

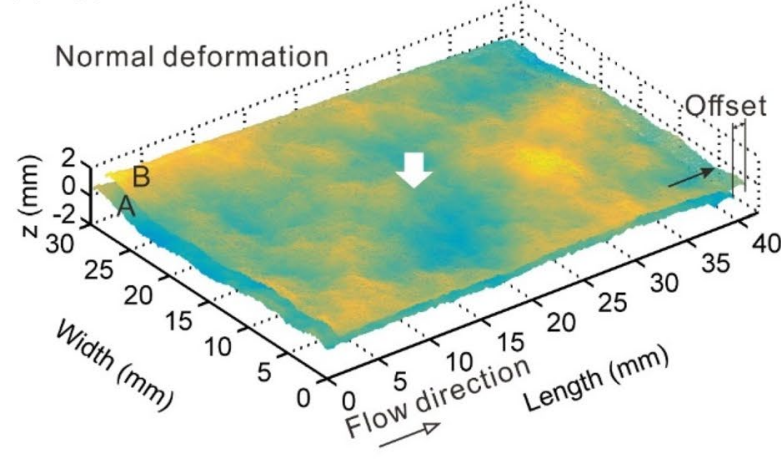

Fig. 3 Schematic illustration of fracture aperture determination using the representative example of sample FOF2. a The upper fracture surface is displaced along the sample length relative to the lower surface. b A fracture aperture distribution with an offset of $1.1759 \mathrm{~mm}(50$

incapable of accounting for loading-unloading cycles that comprise both elastic and irreversible deformation. In this study, the aim is to analyze how the geometrical parameters affect aperture closure to better understand the corresponding experimental results. The interpenetration model was applied in all surface analyses and only geometrical variations and fracture deformation were considered. Figure $3 \mathrm{~b}$ shows an example of the aperture distribution and the areas of contact for a fracture with an offset. The contact area ratio is expressed as,

$R_{\mathrm{c}}=A_{\mathrm{c}} / W(L-\delta)$,

where $A_{c}$ is the contact area.

\subsection{Determination of the Fracture Characteristics using X-Ray $\mu C T$ Scans}

To investigate the microstructural changes of the fracture before and after the experiments, the assembled samples were scanned using an X-ray $\mu \mathrm{CT}$ scanner (GE Phoenix nanotom $\mathrm{m} \mathrm{180)}$ at atmospheric conditions. All scans were performed with dried but jacketed sample cores using the same scanning parameters (i.e., timing $500 \mathrm{~ms}$, voltage: $120 \mathrm{kV}$, current: $90 \mu \mathrm{A}$, and same sample position relative to the X-ray source and detector) to obtain comparable results. A total of 1080 two-dimensional slices with a voxel size of $20.63 \mu \mathrm{m}$ were obtained for each scan and were then used to reconstruct the three-dimensional models. The fracture void spaces $V_{\text {f-ct }}$ were detected and extracted from the corresponding models and the respective mean mechanical apertures $b_{\mathrm{m}-\mathrm{ct}}$ were derived from the following equation:

$b_{\mathrm{m}-\mathrm{ct}}=\frac{V_{\mathrm{f}-\mathrm{ct}}}{A_{\mathrm{f}-\mathrm{ct}}}$, (b) Aperture distribution

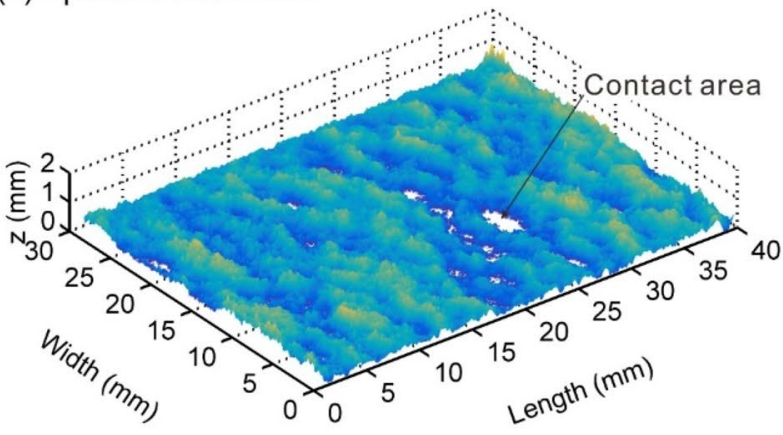

steps of displacement) is shown as an example. The contact area is determined for the deformed state of the fracture surfaces resulting from the applied normal stress

where $A_{\mathrm{f}-\mathrm{ct}}$ is the area of the projection of the 3-D fracture void, which is oriented in parallel to the nominal fracture plane. In addition, the extracted 3-D fracture void was projected onto the nominal fracture plane from which the contact areas $A_{\text {c-ct }}$ were further derived (Fig. 11). The contact area ratio $R_{\mathrm{c}-\mathrm{ct}}$ was then calculated from,

$R_{\mathrm{c}-\mathrm{ct}}=A_{\mathrm{c}-\mathrm{ct}} / A_{\mathrm{f}-\mathrm{ct}}$.

Note that due to the voxel size limit of the reconstructed CT models (voxel sizes in xyz-directions: $20.63 \mu \mathrm{m}$ ), fracture apertures smaller than the voxel size could not be accurately detected. Thus, the fracture aperture might be underestimated in contrast to the contact area ratio, which may be overestimated with this method. Also, the results are numerical products that potentially are not fully equivalent to the true physical parameters. The comparison of the aperture data provides an overall understanding of how the fracture permanently deforms when subjected to normal tress. Not least, the $\mu \mathrm{CT}$ scans were performed at zero-stress and dry conditions. Thus, the fracture apertures at experimental in situ conditions may also show discrepancies with the measured ones.

\section{Results}

\subsection{Hydraulic and Mechanical Aperture Changes during Loading-Unloading Cycles}

The evolution of hydraulic apertures (calculated with Eq. 2) of Flechtinger and Fontainebleau sandstones resulting from the loading-unloading cycles is displayed in Fig. 4. One notices that the initial hydraulic apertures of the mismatched tensile fractures are significantly larger 

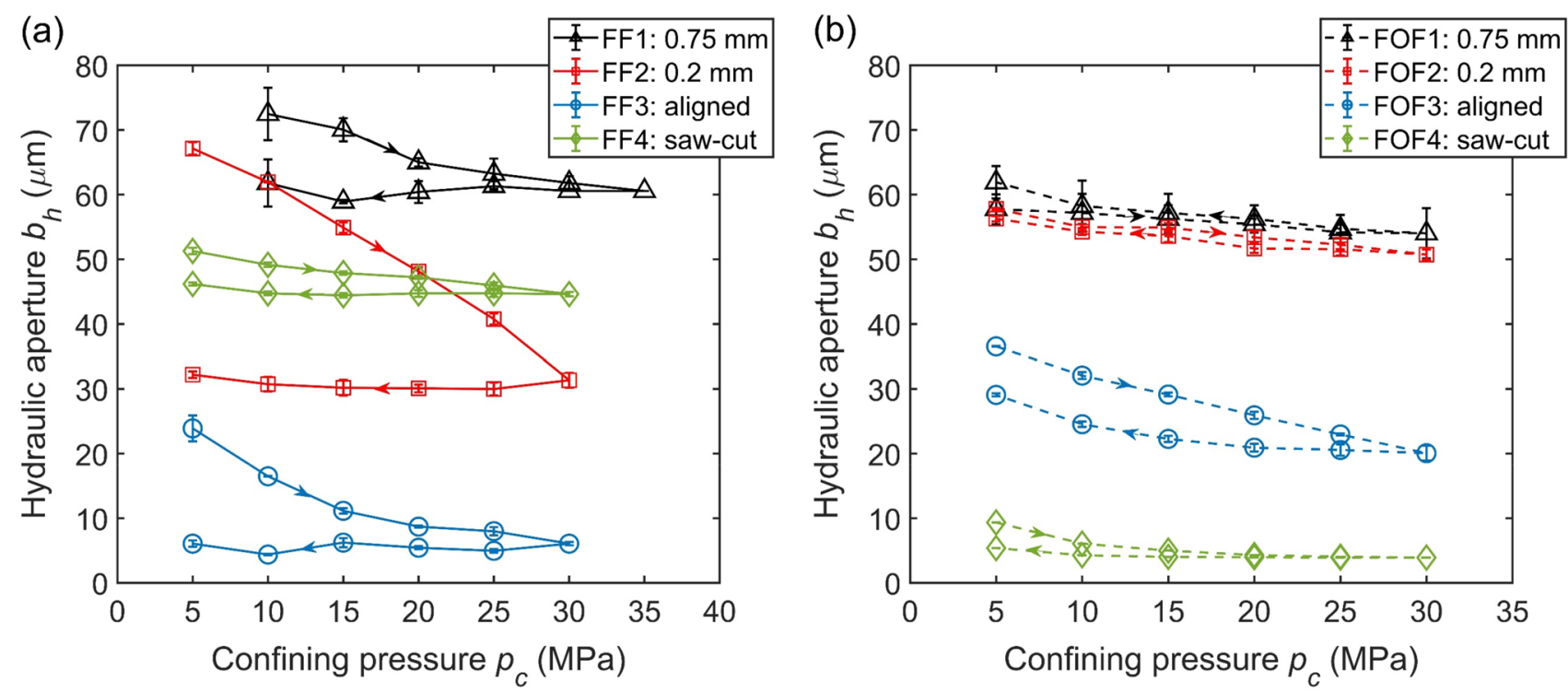

Fig. 4 Hydraulic aperture $b_{\mathrm{h}}$ as a function of confining pressure for a Flechtinger sandstone samples and $\mathbf{b}$ Fontainebleau sandstone samples

than those of both the aligned and the saw-cut fractures for both rock types. The lowest sample permeabilities (calculated with Eq. 1) of FF3 (aligned) and FOF4 (sawcut) at stressed conditions are approximately $4 \times 10^{-16} \mathrm{~m}^{2}$ and $2 \times 10^{-16} \mathrm{~m}^{2}$, respectively, and thus still two orders of magnitude larger than the corresponding matrix permeability $\left(\sim 1 \times 10^{-18} \mathrm{~m}^{2}\right)$, indicating that the introduced fractures are the dominant flow paths even for the smallest fracture apertures and that all fractures are far from being completely closed. Further, it is found that the initial hydraulic aperture increases with an increase of the fracture wall offset. However, the increment of the offset does not proportionally relate to the increment of the initial hydraulic aperture, as distinctly shown in Fig. 4b, where the samples FOF1 and FOF2 with offsets of $0.75 \mathrm{~mm}$ and $0.2 \mathrm{~mm}$, respectively, have an almost identical initial hydraulic aperture. For the two saw-cut samples it showed that the hydraulic aperture of FF4 is about one order of magnitude larger than that of FOF4, which mainly should be the result of differences in fracture surface roughness as related to the intrinsic rock microstructure, e.g., grain size distribution and porosity (Sect. 3.2).

Hydraulic aperture decreased with increasing confining pressure during loading for all samples. Most experiments display a hysteretic behavior during the stress cycle in a way that the respective aperture is larger during loading than during unloading at the same stress level, except for sample FOF1, whose hydraulic aperture was slightly enhanced after unloading. It is noticed further, that for most samples, except for FF2 and FOF3, the hydraulic aperture decrease tends to converge, where a further stress increase results in progressively less reduction in hydraulic aperture.
Finally, irreversible hydraulic aperture changes after the loading-unloading cycles are larger in Flechtinger sandstone samples in comparison to the corresponding Fontainebleau sandstone samples with the same respective offset.

The drained compression tests for determining the variations in mean mechanical aperture started from $p_{\mathrm{c}}=5 \mathrm{MPa}$ or $p_{\mathrm{c}}=10 \mathrm{MPa}$ (FF1). Therefore, the mechanical aperture changes between ambient pressure and $p_{\mathrm{c}}=5 \mathrm{MPa}$ were not measured. Hence, changes in mean mechanical aperture were obtained relative to the respective starting point. The correlation between the mean mechanical aperture changes (calculated with Eq. 4) and the confining pressure, as illustrated in Fig. 5, indicates that these aperture variations are significantly larger than the corresponding hydraulic ones (Fig. 4). Similarly, the mean mechanical apertures of all samples decreased with increasing confining pressure and also clearly depict the formerly observed hysteretic behavior during loading and unloading. Irreversible partial closure of the fracture after the respective loading-unloading cycle occurred in all samples, most pronounced in FF2, except in FOF4. Excluding FF1, which is not directly comparable since the confining pressure range is $10 \leftrightarrow 35 \mathrm{MPa}$, the total variations in mean mechanical aperture of the mismatched fractures are significantly larger than those of the aligned fractures in both rock types. Again, the amount of irreversible fracture closure in the saw-cut sample FF4 is significantly larger than that in FOF4. It is further noticed that even for the same fracture setting (i.e., tensile or saw-cut, identical fracture wall offset), the deformation of the fractures in the two rock types differs significantly. Not least, this emphasizes the dominant role of, both, the rock's mechanical 
(a)

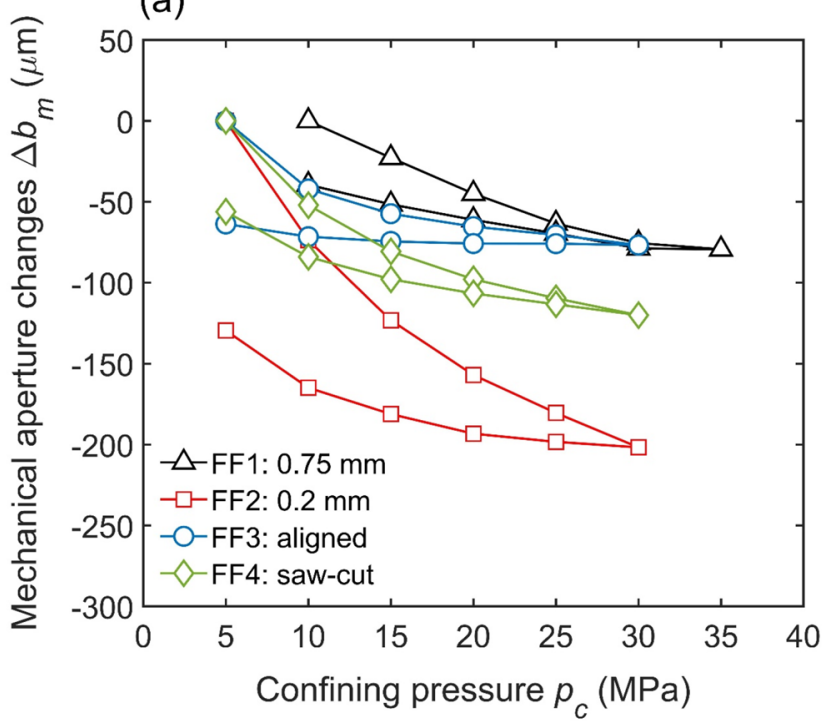

(b)

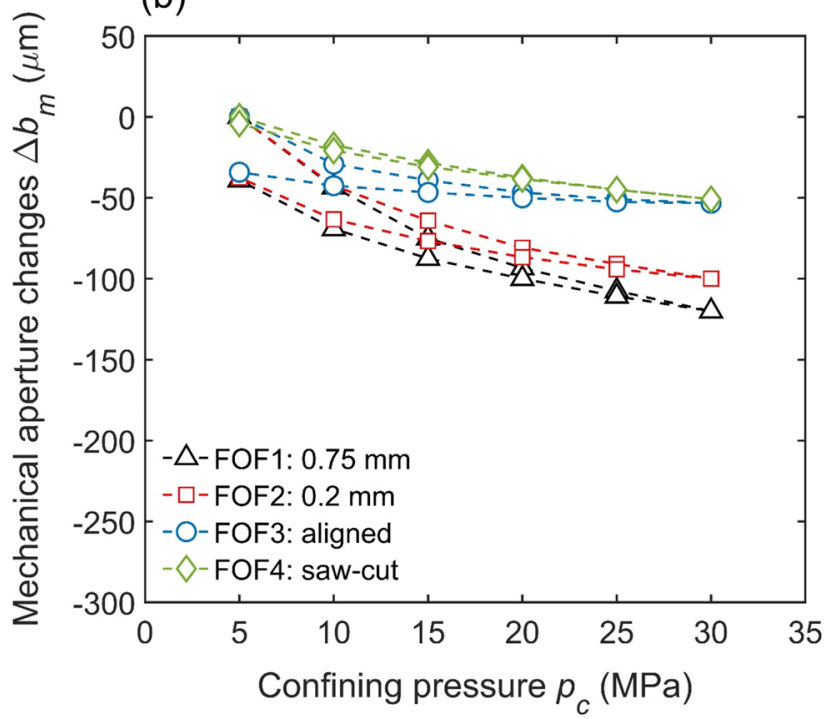

Fig. 5 Mechanical aperture changes $\Delta b_{\mathrm{m}}$ as a function of confining pressure for $\mathbf{a}$ Flechtinger sandstone samples and $\mathbf{b}$ Fontainebleau sandstone samples

properties as well as the fracture's surface roughness in the deformational response of a fracture to changes in stress.

\subsection{Surface Roughness}

Figure 6 shows 3-D views of the scanned fracture surfaces and the corresponding central profiles along the specimen for samples FOF4 and FF4 (saw-cut fractures) as well as FOF2, FOF3, FF2, and FF3 (tensile fractures). The statistical parameters of the fracture surface roughness, as calculated with Eqs. (5-7), are listed in Table 2. It should be noted that these parameters are scale-dependent and related to the length scales of the measured data (i.e., the separation distance between two adjacent points in the raw surface data). However, all surfaces were measured at the same scale and with the same resolution (i.e., $23.518 \mu \mathrm{m}$ on the $x-y$ plane and $1 \mu \mathrm{m}$ in the vertical direction). This resolution proved appropriate to observe most of the microstructural features (Fig. 1) and also permits a direct comparison between samples.

The scanned surface data quantify the roughness of the different fracture types. Saw-cut fractures of both rock types are much smoother than all tensile fracture surfaces. $R_{\mathrm{m}}$ and $R_{\mathrm{rms}}$ of FOF4 and FF4 are almost one order of magnitude smaller in comparison to the corresponding values of the tensile fractures. However, the fracture surface of FOF4 is significantly smoother compared to the FF4 surface, which is also directly visible in Fig. 6a, b. Again, for saw-cut samples, this implies a significant effect of the respective rock microstructure (e.g., grain size distribution and porosity; Fig. 16) on the fracture's surface topography. For tensile fractures, surface roughness varies slightly between samples within one order of magnitude.

Figure 7 shows the 1-D power spectra of the central profiles of the fractures presented in Fig. 6. It is noticed that unlike for many igneous rocks such as granite, where the Hurst exponent $H$ was found to be approximately 0.8 (e.g., Boffa and Allain 1998; Schmittbuhl et al. 2008), suggesting that the fracture surfaces obey a universal invariance over a larger scale, the present fractures in sandstones likely have two main scaling regimes (Table 2). These two main scaling regimes display a larger slope at the smaller wavelengths and a smaller slope at the larger wavelengths. For tensile fractures, the Hurst exponent (Eq. 9, derived from the slopes in Fig. 7) takes a value of $H_{1}=0.54 \pm 0.04$, distinctly smaller than $H_{2}=3.34 \pm 0.21 . H_{1}$ shows a good agreement with previous studies on sandstone samples $(H$ $\approx 0.5$ for a wavelength larger than the cut-off wavelength, i.e., the grain size) (Boffa and Allain 1998; Ponson et al. 2007), which indicates that fractures in tight sandstones are not self-affine on all scales but that a self-similarity may only be valid within a certain range, again, different from igneous rocks. Moreover, the crossover wavelength can be well characterized by an intersection wavelength $\lambda^{*}$ between about 300-400 $\mu \mathrm{m}$, which is about twice the average grain size and roughly equal to the largest grain size (Fig. 1). At characteristic length scales below $\lambda^{*}$, the fracture surface roughness is not self-affine.

Particularly for saw-cut fractures, a tendency of the power spectrum to flatten out (i.e., the roll-off region) is observed 
(a) FOF4: saw-cut
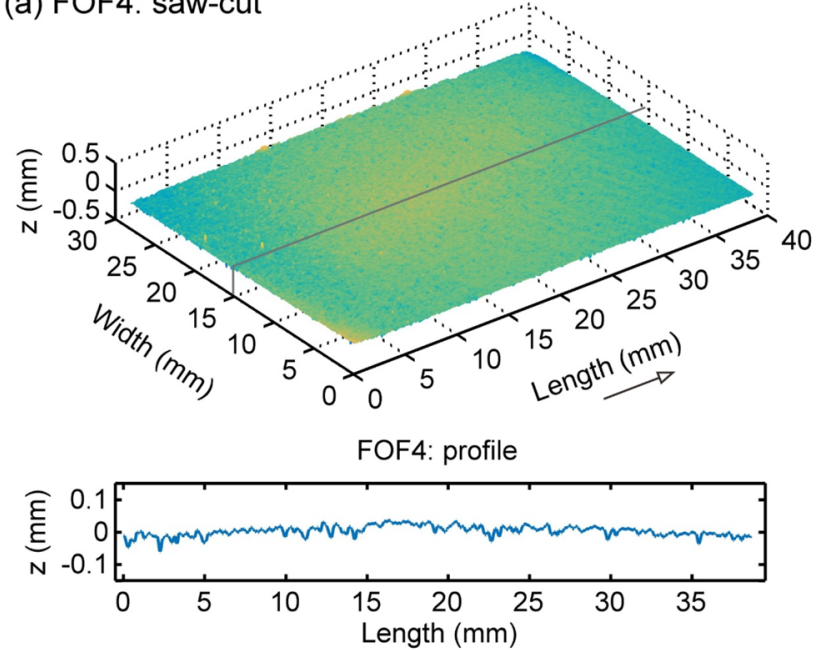

(c) FOF3: tensile

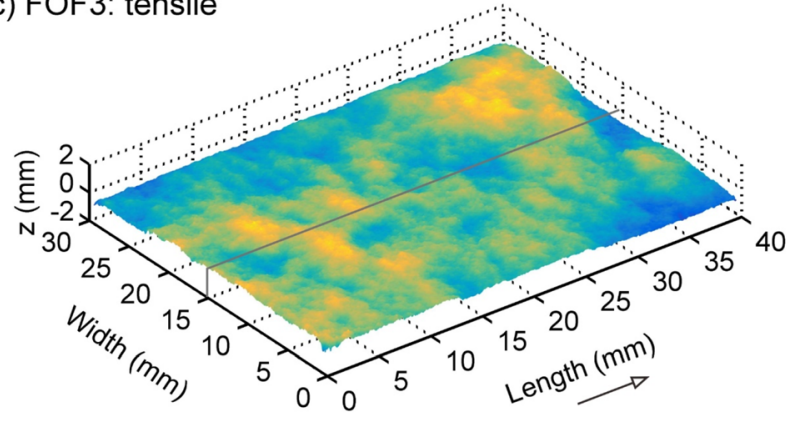

FOF3: profile

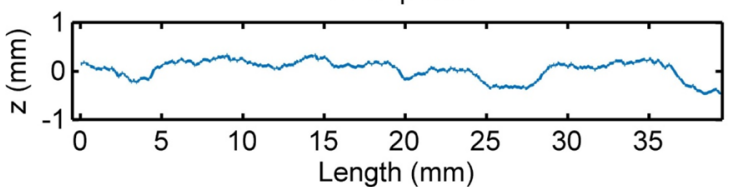

(e) FOF2: tensile

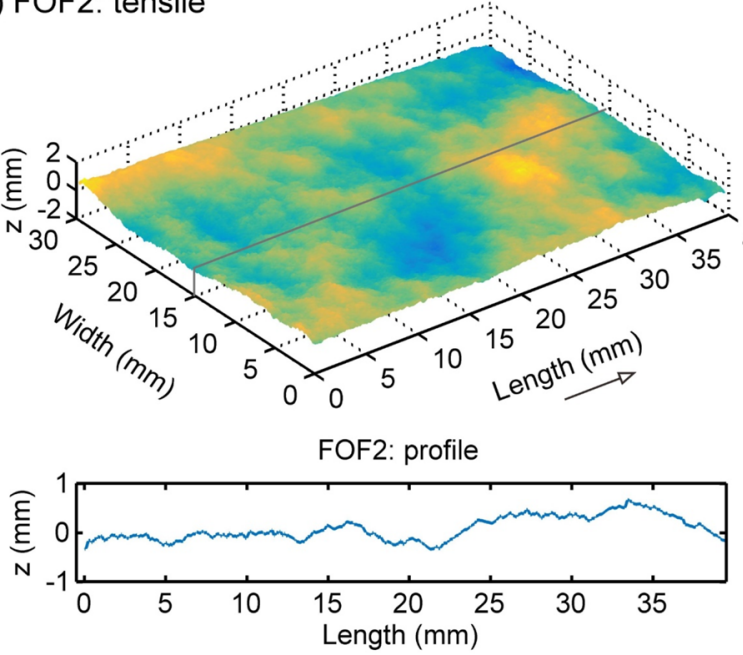

Fig. 6 3-D views of the fracture surfaces of the scanned specimens and their corresponding central profiles along the sample length. The arrows indicate the flow direction in the experiments. a FOF4 sawcut smooth fracture surface; b FF4 saw-cut rough fracture surface; c
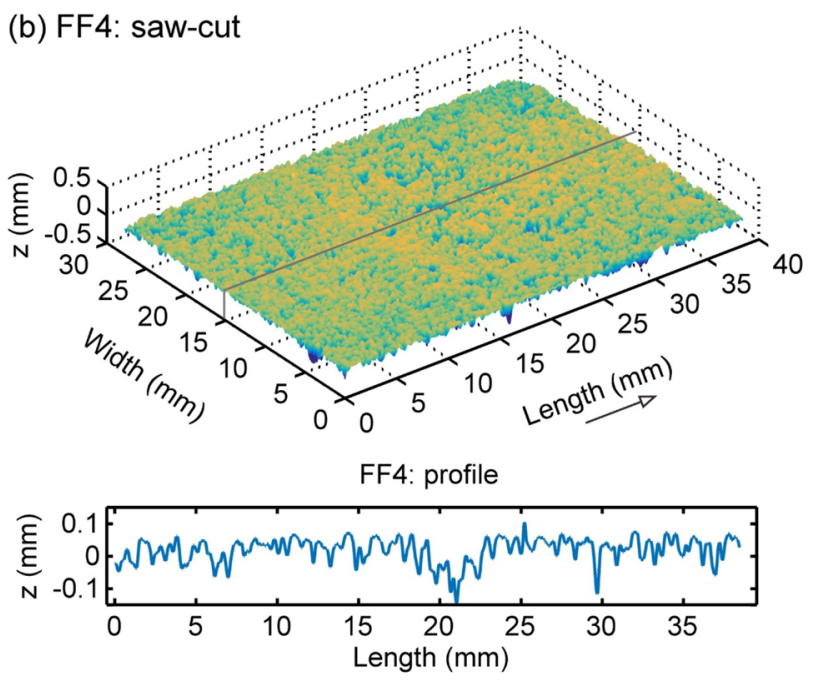

(d) FF3: tensile
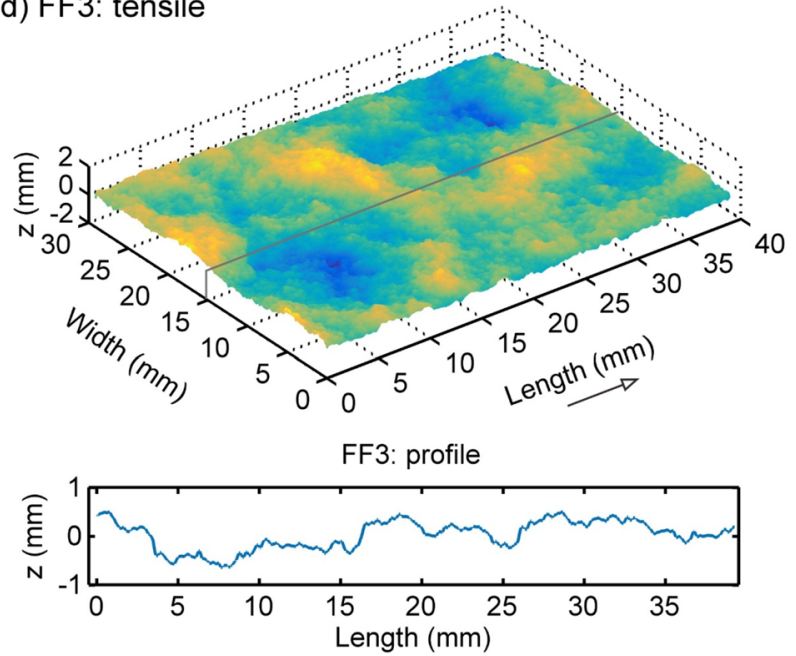

(f) FF2: tensile
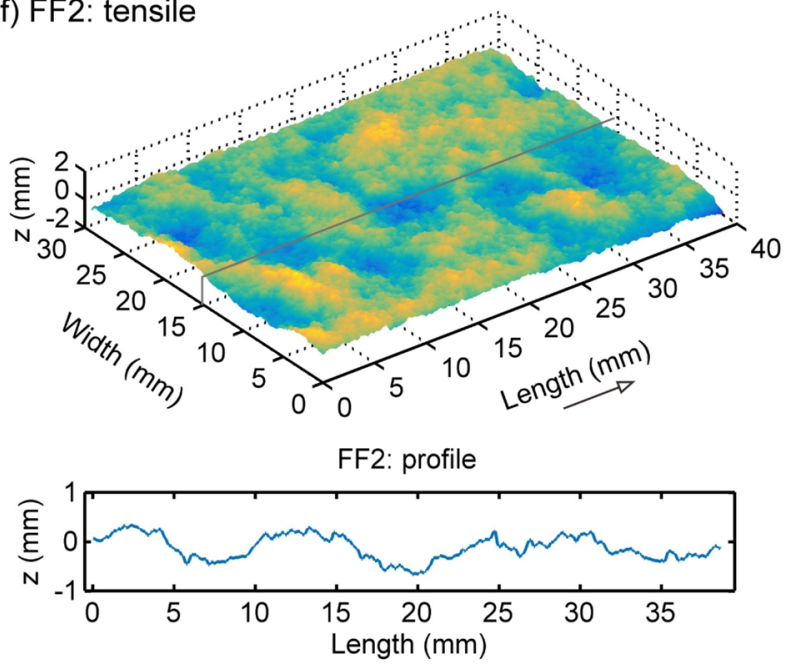

FOF3 tensile Fontainebleau fracture surface; d FF3 tensile Flechtinger fracture surface; e FOF2 tensile Fontainebleau fracture surface; f FF2 tensile Flechtinger fracture surface 
Table 2 Statistical surface roughness parameters of selected samples (Eqs. 5-7)

\begin{tabular}{llllllc}
\hline Parameters & FF2 & FF3 & FF4 & FOF2 & FOF3 & FOF4 \\
\hline$R_{\mathrm{p}}(\mathrm{mm})$ & 0.810 & 1.155 & 0.388 & 0.935 & 0.685 & 0.167 \\
$R_{\mathrm{m}}(\mathrm{mm})$ & 0.194 & 0.251 & 0.034 & 0.214 & 0.152 & 0.011 \\
$R_{\mathrm{rms}}(\mathrm{mm})$ & 0.238 & 0.317 & 0.044 & 0.267 & 0.191 & 0.015 \\
$H_{1}(-)$ & 0.56 & 0.58 & -0.08 & 0.50 & 0.55 & -0.24 \\
$H_{2}(-)$ & 3.55 & 3.49 & 3.37 & 3.13 & 3.14 & 2.86 \\
\hline
\end{tabular}

Note: $H_{1}$ and $H_{2}$ represent the Hurst exponents for small and large wavevectors, respectively (Fig. 7). In the regimes of $\mathrm{H}_{2}>1$, the spectra do not follow a self-affine-like power-law, which implies that the surface cannot be classified as fractal. A negative $H_{1}$ in saw-cut fractures indicates a roll-off wavevector region as the wavelength increases above a certain wavelength $\lambda^{*}=420-430 \mu \mathrm{m}$, which corresponds to the largest grain size. Since power is proportional to the roughness amplitude, one consequence of this is that the fracture surfaces are independent of the observational length $l$ for $l \gg \lambda^{*}$ (Persson et al. 2004).

\subsection{Numerical Fracture Apertures}

The initial mean mechanical aperture (calculated with Eq. 10) between the two adjacent fracture surfaces of the selected samples was derived as a function of the fracture wall offset, as shown in Fig. 8a. The mean mechanical aperture of all tensile fractures, initially, drastically increases with increasing offset and then progressively tends to converge, where a further increase of the displacement yields only small aperture fluctuations. Thus, the trend can be roughly classified into three regimes as shown in Fig. 8a. This is consistent with experimental observations regarding the shear dilation of fractures (Chen et al. 2000). In a theoretical study, Plouraboué et al. (1995) concluded that a rigid mechanical aperture with ongoing horizontal displacement is supposed to scale as $b_{\mathrm{m}} \propto Z \delta^{H}$ if the fracture surfaces are self-affine and invariant over a larger scale (e.g., $H=0.83$ for a granite fracture investigated in the cited study). Here, $Z$ is a correction term which is inversely proportional to the displacement $\delta$. The present results indicate that the fracture aperture variations cannot be described by a simple power law (Fig. 8b). In addition, the self-affinity is only valid when the wavelength $>\lambda^{*}$. For $\delta<\lambda^{*}$, this may not strictly apply, in contrast to Plouraboué et al. (1995). Furthermore, it was found that the fracture aperture remains approximately constant when further displacing the surface beyond one-tenth of the sample size.

The respective convergence aperture values of each rock sample are directly related to the individual fracture's surface roughness. In contrast, for the saw-cut fractures FF4 and FOF4, the initial mechanical apertures show to be more or less independent of the offset, resulting from the existence of a roll-off wavelength (Sect. 3.2), which is consistent with the mathematical analyses of Plouraboué et al. (1995). Here, the initial mechanical aperture is only determined by the surface roughness, which is related to the intrinsic microstructure of the rock matrix. Accordingly, the average $b_{\mathrm{m}}$ of FF4 and FOF4 during shearing from 0 to $4 \mathrm{~mm}$ (i.e., one-tenth of the sample length), as calculated based on the surface models, are $0.42 \mathrm{~mm}$ and $0.09 \mathrm{~mm}$, respectively. In addition, the mean $b_{\mathrm{m}}$ of FF2 and FOF2, which were calculated with a pre-offset of $0.2 \mathrm{~mm}$, equivalent to the true experimental setting, are $0.4086 \mathrm{~mm}$ and $0.2584 \mathrm{~mm}$, respectively. Figure 8c shows a comparative (numerical) example of the variations in aperture distribution of sample FOF2 for two different offsets (i.e., $0.2 \mathrm{~mm}$ and $0.75 \mathrm{~mm}$ ).

By applying the interpenetration model to the fracture surfaces (Sect. 2.3.2), one further obtains the evolution of the mean mechanical aperture as a function of the contact area ratio (Eq. 11), as shown in Fig. 9. The initial apertures of the aligned saw-cut fractures in FF4 and FOF4 are $0.517 \mathrm{~mm}$ and $0.0868 \mathrm{~mm}$, respectively. For tensile fractures, Fig. 9b demonstrates that a decrease of the mean mechanical aperture leads to a nonlinear increase in contact area ratio. It is inferred that the residual mechanical aperture and thus the maximum aperture closure value are proportional to the initial mechanical aperture, which well explains the differences in fracture aperture changes observed in the experiments (Fig. 5).

\subsection{Evolution of Fracture Aperture and Contact Area Ratio based on X-ray $\mu \mathrm{CT}$}

The initial and final fracture apertures were determined based on the 3-D reconstructed $\mu \mathrm{CT}$ models shown in Fig. 10. As an exception, the samples FF4 and FOF4 were only scanned before the experiment. It is noticed that all tensile fractures show a substantial change after the experiments, where the contact area has drastically increased. For the aligned tensile fractures FF3 and FOF3, the aperture uniformly decreased so that the residual voids, as detected in the models, appear disconnected after the experiment. Although the initial (unstressed) mechanical aperture can be determined by the CT scans, there is a remaining observational gap between zero-stress conditions and the experimental 

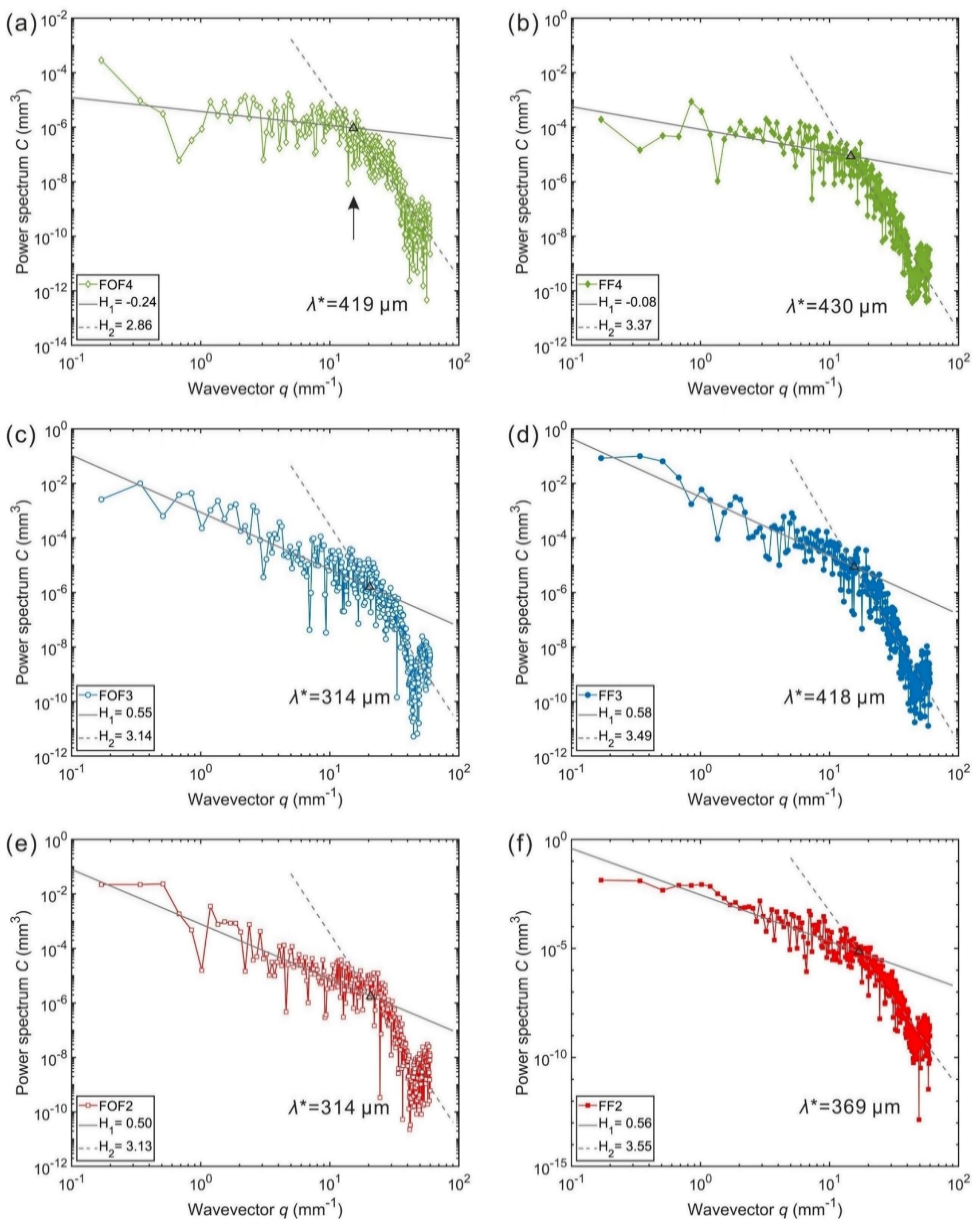

Fig. 7 1-D surface roughness power spectra of the central profiles in the direction parallel to the displacement of fracture surfaces in a FOF4, b FF4, c FOF3, d FF3, e FOF2, and f FF2 (see Fig. 6), where

$H_{1}$ and $H_{2}$ represent the Hurst exponents for small and large wavevectors, respectively, and $\lambda^{*}$ indicates the crossover (black triangles) of the two regimes 


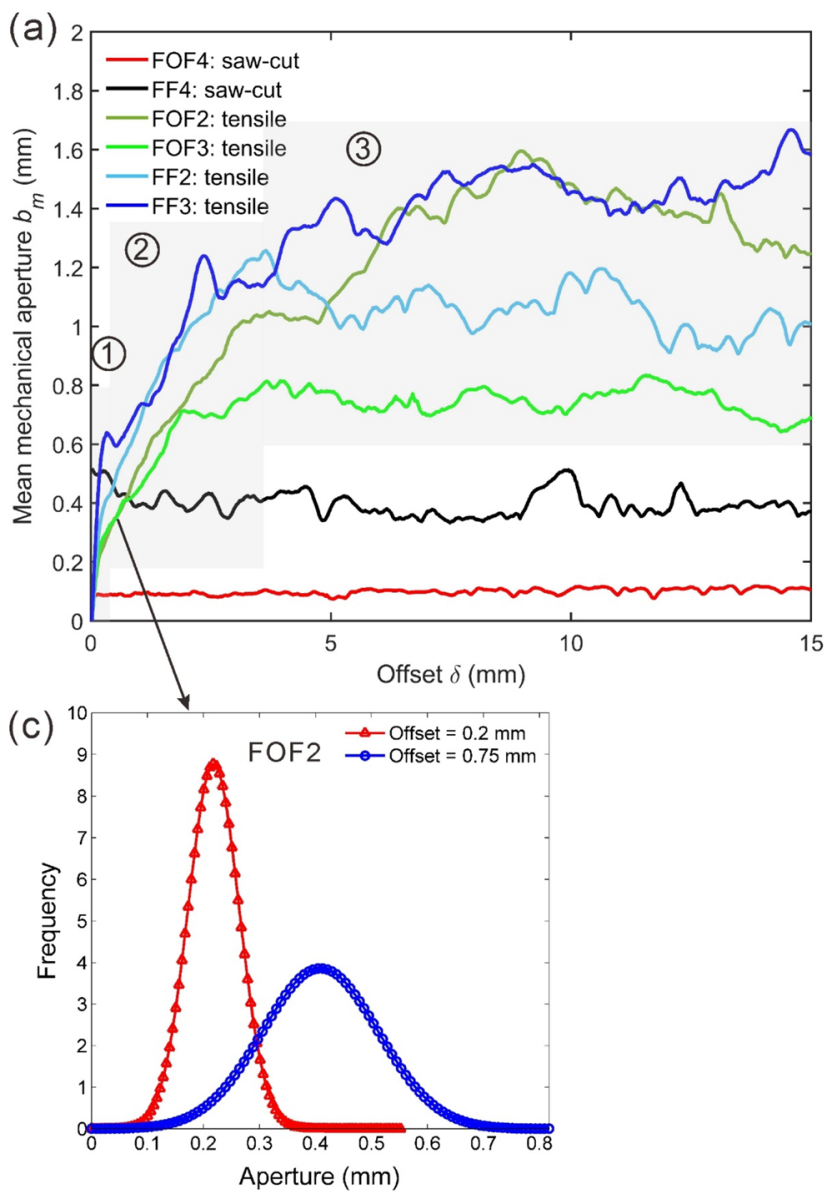

Fig. 8 a Evolution of the initial mean mechanical aperture with increasing offset of the two adjacent fracture surfaces along the sample length. b Log-log plot of the initial mean mechanical aperture with normalized offset $\delta / L$. The dotted line indicates a simple power

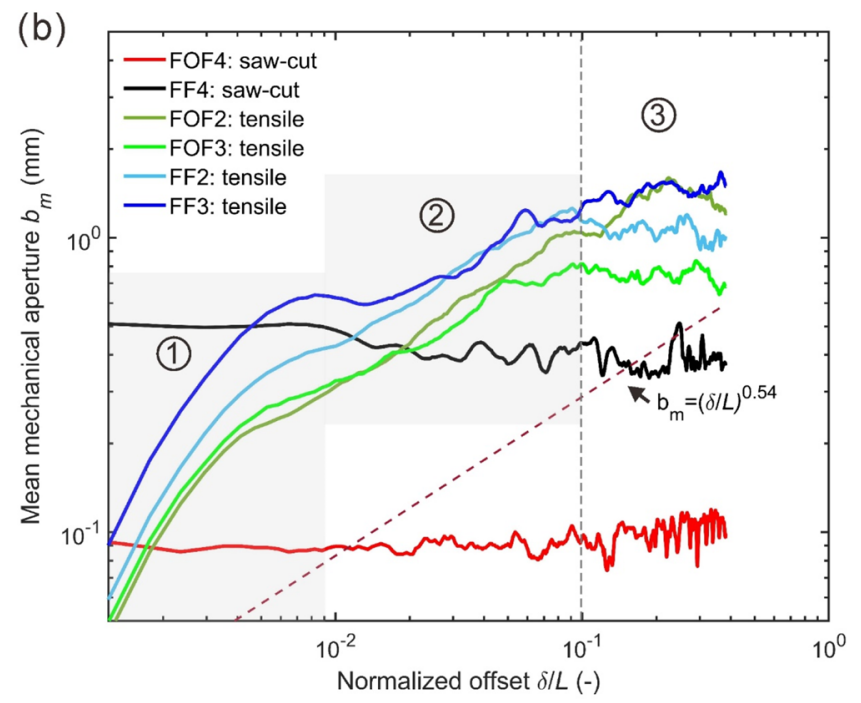

law, $b_{\mathrm{m}}=(\delta / L)^{H}$, where $H=0.54$ corresponds to the present sandstones (Fig. 7). c Representative aperture distributions of sample FOF2 with offsets of $0.2 \mathrm{~mm}$ and $0.75 \mathrm{~mm}$, respectively (a)

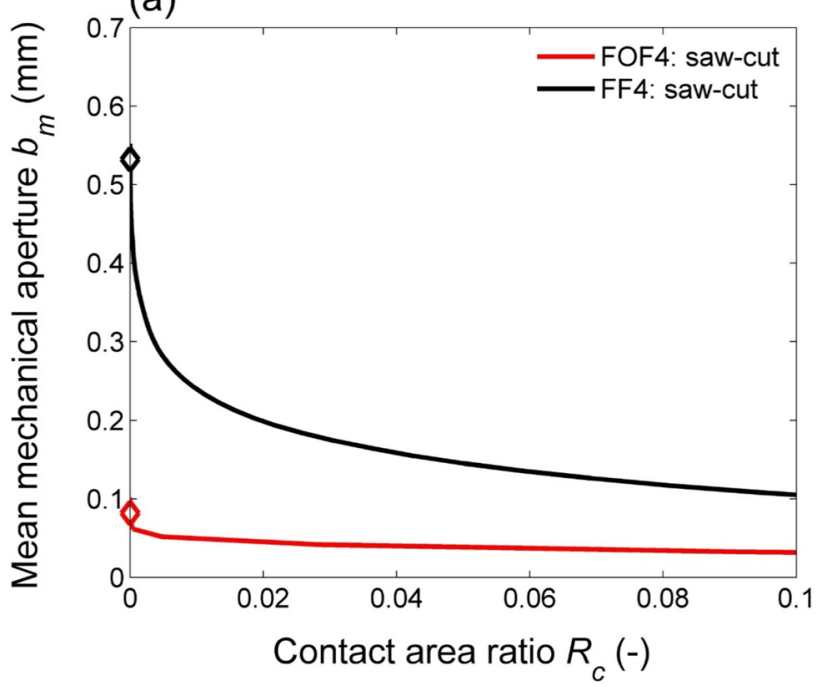

(b)

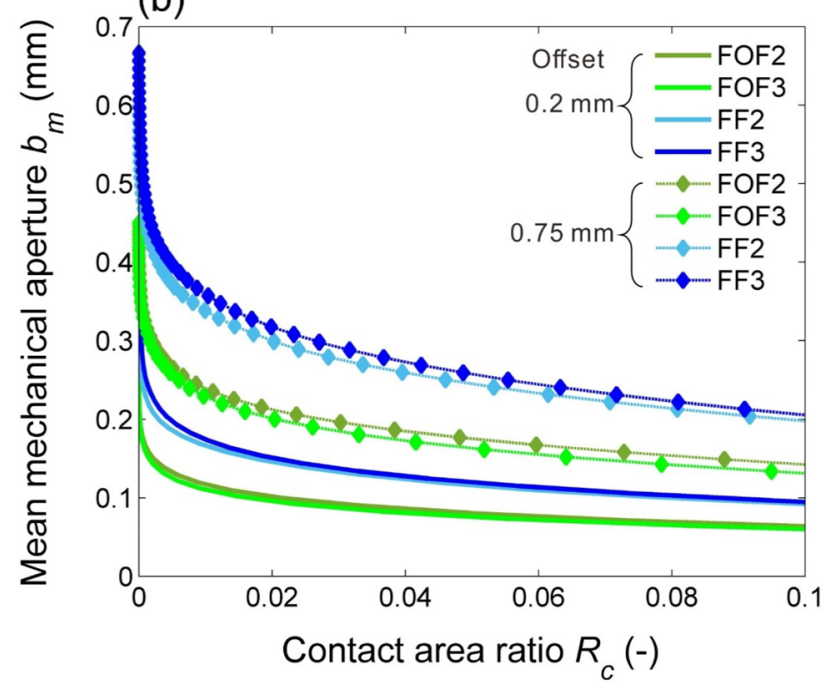

Fig. 9 Variations of the mean mechanical aperture $b_{\mathrm{m}}$ (Eq. 10) with increasing contact area ratio $R_{\mathrm{c}}$ (Eq. 11) for a saw-cut fractures in FF4 and FOF4 and $\mathbf{b}$ tensile fractures in FF2, FF3, FOF2, and FOF3 
Fig. 10 3-D reconstructed models of the assembled dry rock samples of Flechtinger sandstones $\mathbf{a}$ before and $\mathbf{b}$ after the experiments as well as Fontainebleau sandstones $\mathbf{c}$ before and $\mathbf{d}$ after the experiments, respectively. The images were obtained from X-ray $\mu \mathrm{CT}$ scans at atmospheric conditions. The fracture void spaces (in blue) of each sample were extracted and the pore spaces in the rock matrix (porosity: $8.1 \%$ for Flechtinger samples and 2.5\% for Fontainebleau samples) were considered to be negligible. The areas in the fractures shown in the same color as for the matrix indicate the contacting asperities, where the fracture void space is considered to be zero. The yellow arrow indicates the line of sight perpendicular to the fracture projections displayed in Fig. 11

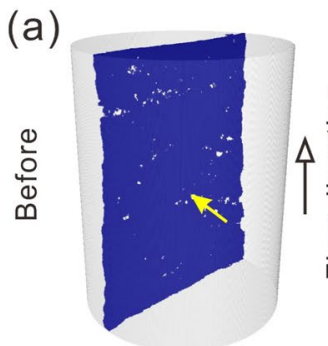

FF1

(b)

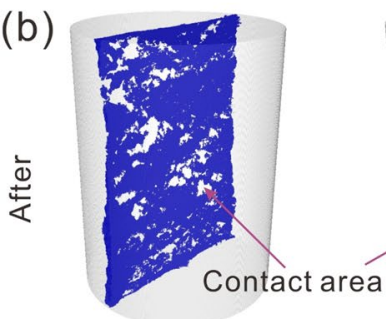

$5 \mathrm{~mm}$

Fracture void

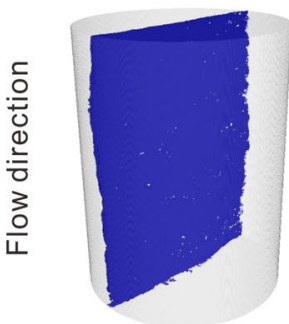

FF2

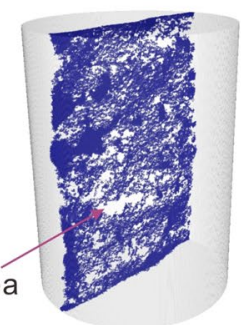

FF3

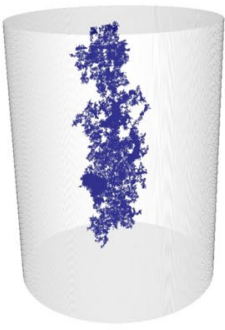

Rock matrix

Fontainebleau Sandstone

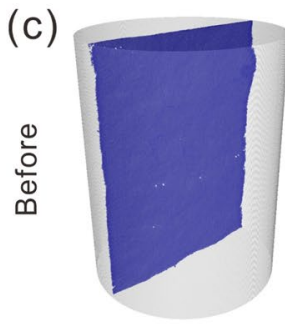

FOF1

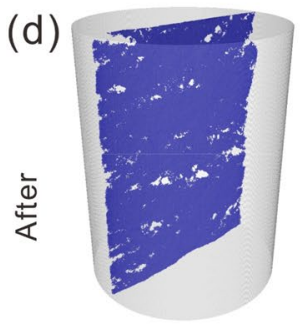

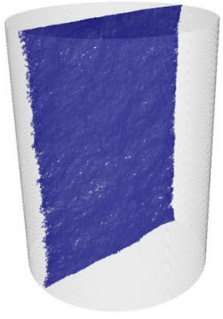

FOF2

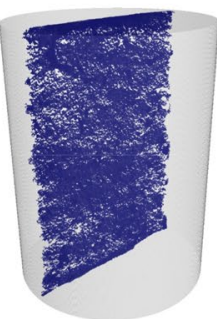

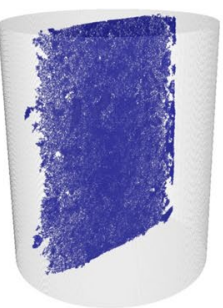

FOF3

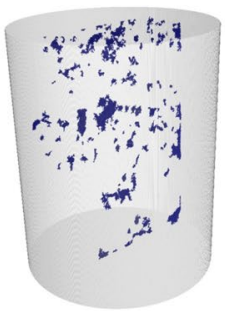

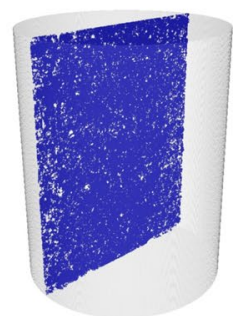

FF4

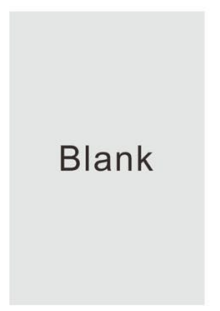

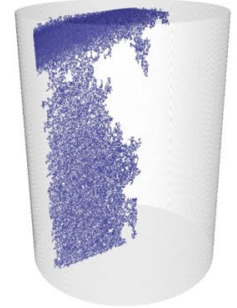

FOF4

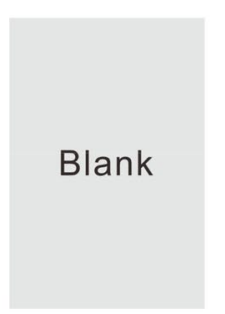

effective starting stress of $4 \mathrm{MPa}$. Therefore, only the initial and final mechanical apertures at atmospheric conditions are compared.

Figure 11 shows the projections of the extracted fracture voids, from which the respective contact area ratio before and after the experiment was derived. The $\mu \mathrm{CT}$-derived contact areas show a good agreement with the observed damage areas in the fracture surfaces after the experiments, particularly for the displaced Flechtinger samples (Fig. 17). The contact areas in the mismatched tensile fractures, representing the permanent damage zones, either enlarged from pre-existing asperities in contact or occurred as new contacts. The contacts are mostly isolated but some asperities have merged resulting in a larger contact area. This is particularly observed in Flechtinger sandstone and in the Fontainebleau sample with the largest offset (FOF1). In addition, the extension of the contact area is oriented perpendicular to the direction of the shear displacement, which is consistent with previous observations (Auradou et al. 2005; Nemoto et al. 2009). Due to resolution limitations, a 
Fig. 112 -D projections of the extracted fracture void space from the $\mu \mathrm{CT}$ models shown in Fig. 10. Flechtinger sandstones $\mathbf{a}$ before and $\mathbf{b}$ after the experiments as well as Fontainebleau sandstones $\mathbf{c}$ before and $\mathbf{d}$ after the experiments, respectively
Table 3 Evolution of mechanical aperture and contact area ratio determined by analyzing the 3-D X-ray $\mu \mathrm{CT}$ models

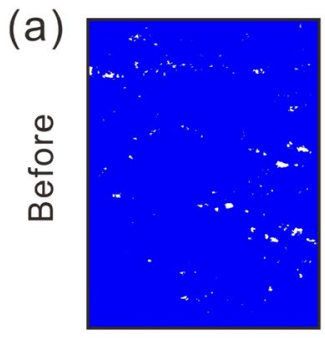

FF1
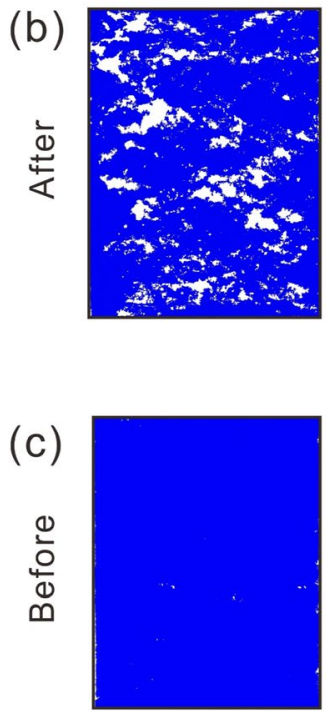

FOF1

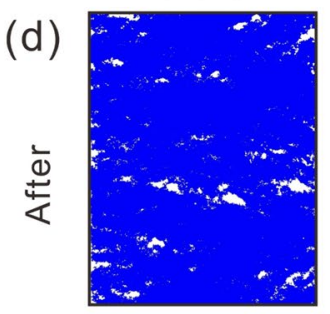

Flechtinger Sandstone

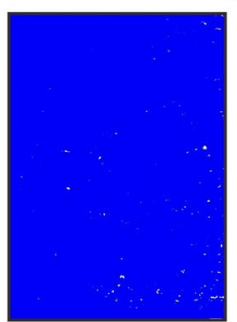

FF2

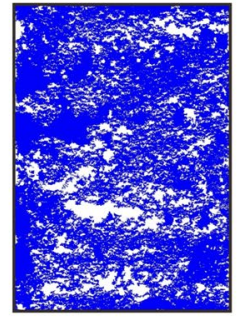

Fontainebleau Sandstone

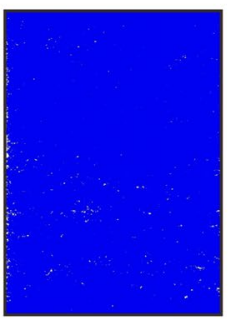

FOF2

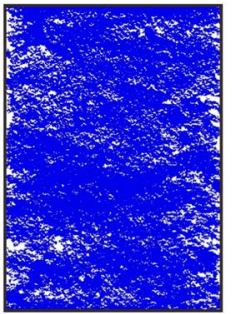

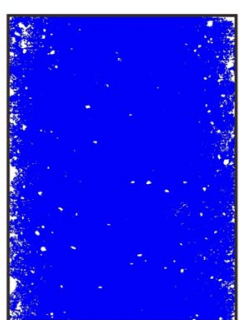

FF3

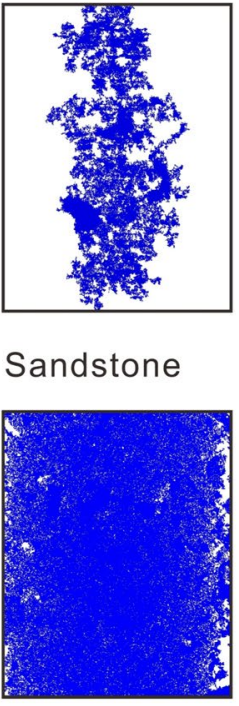

FOF3

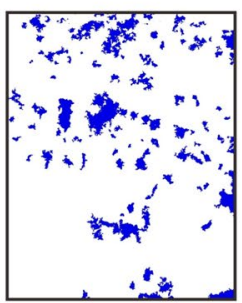

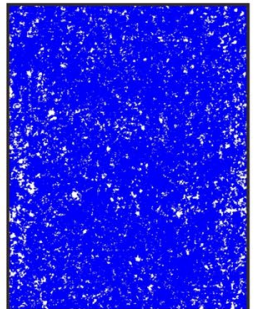

FF4

Fracture void

Contact area

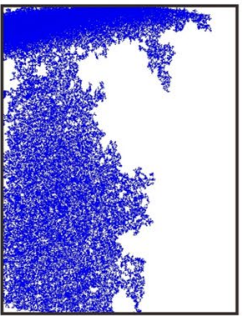

FOF4

\begin{tabular}{|c|c|c|c|c|c|c|c|c|c|}
\hline \multirow[t]{2}{*}{ Sample } & \multirow[t]{2}{*}{ Offset (mm) } & \multicolumn{2}{|c|}{$b_{\mathrm{m}-\mathrm{ct}}(\mu \mathrm{m})$} & \multirow[t]{2}{*}{$\Delta b_{\mathrm{m}-\mathrm{ct}} / b_{\mathrm{m}-\mathrm{ct}}(\%)$} & \multicolumn{2}{|c|}{$R_{\text {c-ct }}(\%)$} & \multicolumn{2}{|c|}{$b_{\mathrm{h}}(\mu \mathrm{m})$} & \multirow[t]{2}{*}{$p_{\mathrm{e}}(\mathrm{MPa})$} \\
\hline & & Before & After & & Before & After & Initial & Final & \\
\hline FF1 & 0.75 & 508.2 & 279.1 & 45.08 & 0.99 & 11.43 & 72.5 & 61.8 & 9 \\
\hline FF2 & 0.2 & 352.9 & 107.6 & 69.51 & 0.36 & 25.11 & 67.1 & 32.2 & 4 \\
\hline FF3 & Aligned & 160.8 & 24.7 & 84.64 & 3.89 & 73.77 & 23.9 & 6.1 & 4 \\
\hline FF4 & Saw-cut & 119.6 & - & - & 9.69 & - & 51.3 & 46.2 & 4 \\
\hline FOF1 & 0.75 & 365.4 & 186.7 & 48.91 & 0.75 & 3.67 & 57.7 & 61.9 & 4 \\
\hline FOF2 & 0.2 & 185.5 & 99.2 & 46.52 & 0.88 & 15.54 & 57.8 & 56.3 & 4 \\
\hline FOF3 & Aligned & 89.3 & 15.3 & 82.87 & 11.33 & 88.26 & 36.5 & 29.1 & 4 \\
\hline FOF4 & Saw-cut & 23.5 & - & - & 61.75 & - & 9.4 & 5.4 & 4 \\
\hline
\end{tabular}

Notes: $b_{\mathrm{m} \text {-ct }}$ and $R_{\mathrm{c}-\mathrm{ct}}$ are the mechanical aperture and the contact area ratio obtained from Eqs. 12 and 13, respectively. $b_{\mathrm{h}}$ is the first and last hydraulic aperture measured at the respective effective stress $p_{\mathrm{e}}$ 
similar analysis of the aligned and the saw-cut fractures was difficult to perform.

Table 3 lists the statistically obtained mean mechanical apertures and contact area ratios of the samples before and after the experiments based on the $\mu \mathrm{CT}$ models and the fracture projections. For both rock types, an increase in the fracture wall offset significantly increases, both, the initial and final apertures and decreases the final contact area ratio. Generally, the mismatched Flechtinger sandstone samples show a larger contact area ratio than the corresponding Fontainebleau sandstone samples. However, a quantitative comparison between samples may lead to misinterpretation due to the differences in surface roughness (Table 2). Finally, when comparing the derived initial and final mechanical apertures and the measured initial and final hydraulic apertures, both, at a given offset and between offsets, it shows that the variability of the mechanical apertures is significantly larger than that of the hydraulic apertures. A direct comparison and validation of mechanical apertures derived from surface topography calculations and $\mu \mathrm{CT}$ models is difficult, as shown in Table 4. This is because of the assumptions of a grid-body and a minimum contact area in surface analyses and the resolution differences between the methods.

\section{Discussion}

\subsection{Correlations Between Hydraulic Aperture and Mechanical Aperture}

For all experiments, the measured hydraulic apertures and the mechanical apertures derived by the drained compression tests (Sect. 3.1) and the $\mu \mathrm{CT}$ scans (Sect. 3.3) showed significant differences. Figure 12 shows the correlation between the changes of the hydraulic and mechanical apertures at effective stresses in the range between 4 and $29 \mathrm{MPa}$ in comparison to a previous study on an aligned and a mismatched granodiorite fracture (Hofmann et al. 2016). It is noticed that the changes of the mechanical and the hydraulic apertures of the aligned fractures are in better agreement compared to the other samples as these data are closer to the " $\Delta b_{\mathrm{h}}=\Delta b_{\mathrm{m}}$ line". In addition, there is no significant

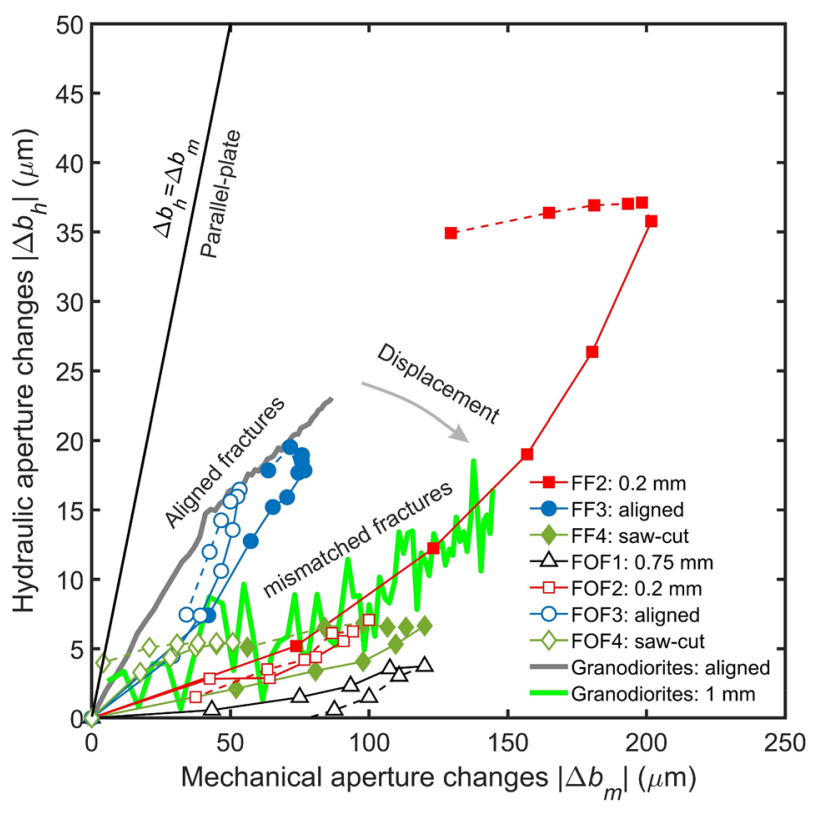

Fig. 12 Changes of hydraulic aperture $\mid \Delta b_{\mathrm{h}} \mathrm{l}$ as a function of mechanical aperture changes $\left|\Delta b_{\mathrm{m}}\right|$ at different effective stresses as calculated from a comparison with the starting values at an effective stress of $4 \mathrm{MPa}$ (loading in solid lines and unloading in dotted lines). Results for an aligned granodiorite fracture and a similar fracture with an offset of $1 \mathrm{~mm}$ at effective stresses in the same range (i.e., between 4 and $29 \mathrm{MPa}$ ) were taken from Hofmann et al. (2016), where confining pressure was continuously varied during the measurements (bold lines), in contrast to the present study where confining pressure was changed stepwise in intervals of $5 \mathrm{MPa}$ (filled and open dots)

difference between the sandstone samples used in this study and the granodiorite rock reported in the literature (Hofmann et al. 2016), even though their mechanical properties are significantly different. Considering a simple linear correlation $\Delta b_{\mathrm{h}}=S \Delta b_{\mathrm{m}}$ during loading (where $S$ is a slope) for all mismatched fractures (including saw-cut fractures, which also represent a kind of mismatch at the microscale) $S_{\text {mis }}<S_{\text {ali }}<1$, indicating that the variations in mechanical aperture are significantly larger than those of the hydraulic apertures, which is also consistent with previous studies on granitic fractures (Durham and Bonner 1994; Chen et al. 2000; Hofmann et al. 2016; Vogler et al. 2016). Moreover, in comparison to $R_{\mathrm{c}-\mathrm{ct}}$ after the experiments (Table 3), it

Table 4 Comparison of initial mechanical apertures obtained from surface topographies (Sect. 3.3) and $\mu$ CT models (Table 3)

\begin{tabular}{lllll}
\hline Methods & FF2 $(\delta 0.2 \mathrm{~mm})$ & FOF2 $(\delta 0.2 \mathrm{~mm})$ & FF4 (saw-cut) & FOF4 (saw-cut) \\
\hline Surface data $b_{\mathrm{m}}(\mu \mathrm{m})$ & 408.6 & 258.4 & 517.0 & 86.8 \\
$\mu \mathrm{CT}$ models $b_{\mathrm{m}-\mathrm{ct}}(\mu \mathrm{m})$ & 352.9 & 185.5 & 119.6 & 23.5 \\
\hline
\end{tabular}


(a)

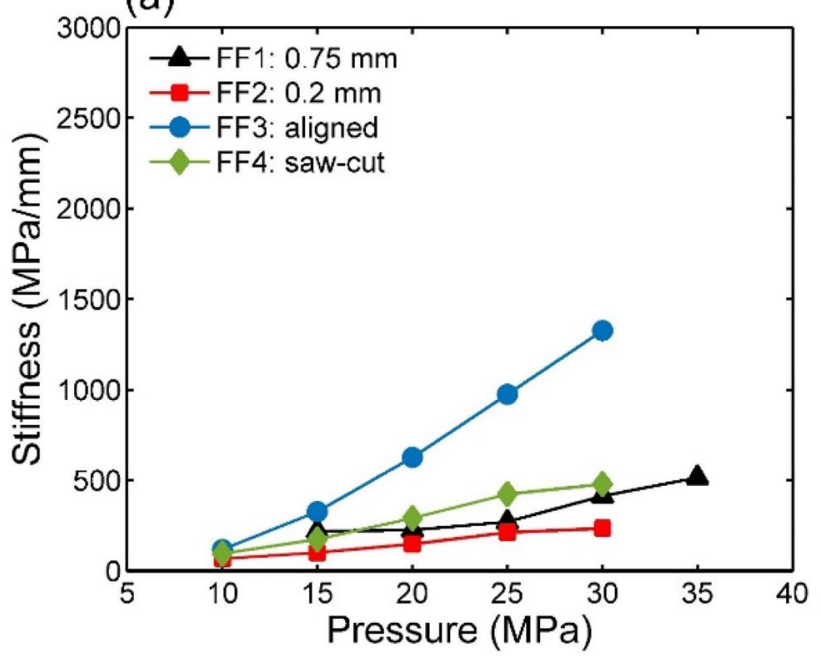

(b)

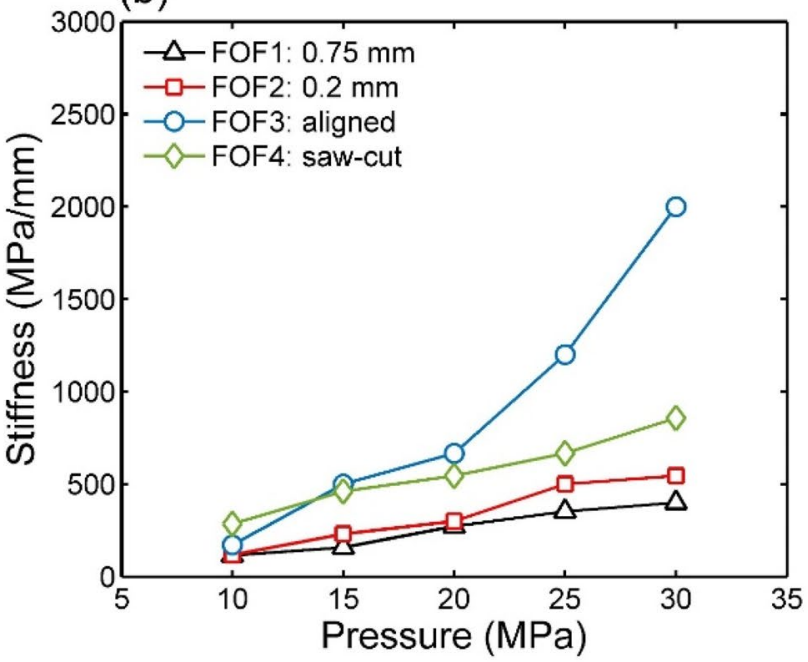

Fig. 13 Normal stiffness of the fractures for a Flechtinger sandstone samples and $\mathbf{b}$ Fontainebleau sandstone samples as a function of confining pressure

is found that $S \propto R_{\mathrm{c}-\mathrm{ct}}$, implying that the contact area ratio controls the slopes of this linear correlation. Furthermore, the range of mechanical aperture changes under stress is proportional to their initial apertures (Table 3).

The main reason for this discrepancy is the assumption of the smooth parallel-plate model "cubic law" for the calculation of the hydraulic aperture (Witherspoon et al. 1980). Fracture surfaces are in contact at the propping asperities, which are local features rather than being expanded over a larger area (Fig. 11). Fracture surfaces are rough rather than ideally smooth and hence fluid flow is tortuous within channels defined by the asperities. Therefore, a reduction of the mechanical aperture induced by stress variations does not have an equivalent effect on the flow channels. However, the aperture of an aligned fracture between the opposing fracture surfaces is likely more uniform and fluid flow may be only affected by the surface tortuosity rather than by flow channels.
Fig. 14 Conceptual model of fracture closure for different fracture types: a ideal smooth fracture; $\mathbf{b}$ aligned rough fracture; $\mathbf{c}$ displaced rough fracture. The respective correlations between hydraulic and mechanical apertures are depicted on the right (a)
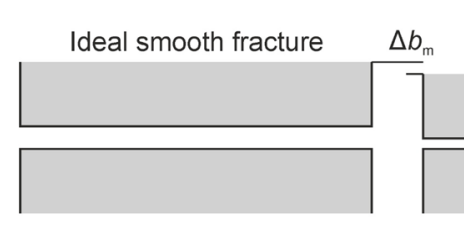

b)
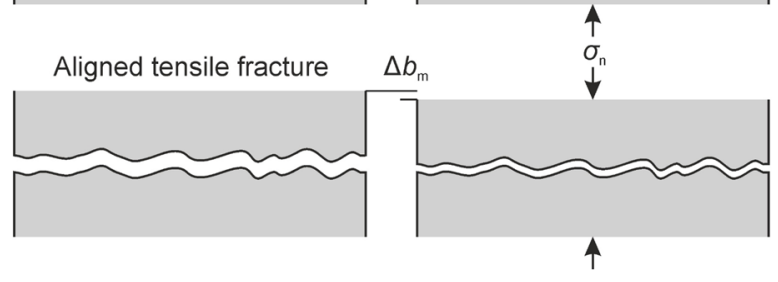

(c)

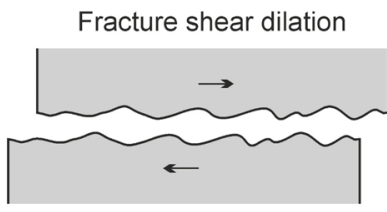

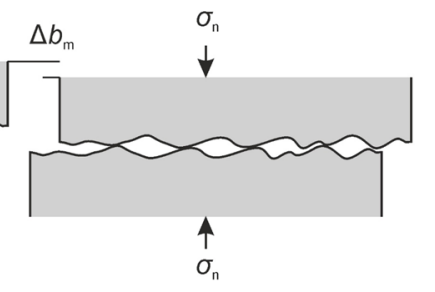
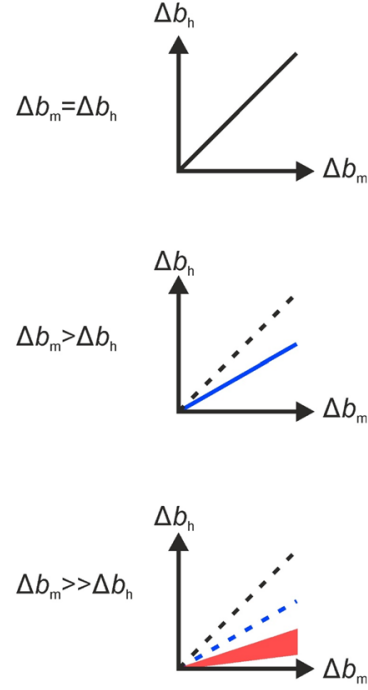
This behavior likely results from the differences in normal fracture stiffness. Figure 13 shows the normal stiffness of the fractures as calculated based on the stress and the deformation of the fractures during loading. The respective stiffness is almost linearly correlated to confining or effective pressure (Raven and Gale 1985) and the slope of the correlation decreases with increasing fracture wall offset. When compared to the contact area ratio (Table 3), the stiffness of the specific rock type shows the same sample order (e.g., $R_{\text {c-ct }}:$ FOF3 $>$ FOF4 $>$ FOF2 $>$ FOF1 and slope of the stiffness-pressure curve: FOF3 $>$ FOF4 $>$ FOF2 $>$ FOF1). Consequently, the fracture stiffness is mainly determined by the contact area ratio and the mechanical properties (e.g., Young's modulus) of the asperities that bear the normal stress. This affects the correlation between $\Delta b_{\mathrm{h}}$ and $\Delta b_{\mathrm{m}}$ significantly.

A conceptual model is proposed to describe the correlation between hydraulic and mechanical aperture changes under normal stress (Fig. 14), where the ideal parallel-plate model is presented as a comparison. An aligned rough fracture yields a large contact area ratio and a small initial aperture due to the matching geometry of the fracture surfaces. The flow is mainly affected by the surface tortuosity and thus the correlation slightly deviates from the ideal case. However, fracture dilation occurs when the surfaces are displaced (Fig. 8a) leading to a larger initial aperture and a smaller contact area ratio (Table 3). Thus, mechanical aperture changes increase under stress. Depending on the strength of the contact asperities to withstand high normal stresses, hydraulic aperture changes much less upon loading. Therefore, the displaced self-propping fractures should possess rather sustainable hydraulic properties under normal stress. The quantitative effects of surface roughness and offset on fracture aperture will be discussed in Sect. 4.2.

Previous theoretical and experimental studies on fluid flow in deformable fractures indicate that the hydraulic aperture can be significantly smaller than the mechanical aperture and a threshold may be reached below which a further reduction in mechanical aperture has no effect on the hydraulic aperture (Raven and Gale 1985; Renshaw 1995). Most existing correlations between hydraulic and mechanical apertures include either the standard deviation of the aperture (Zimmerman et al. 1991; Renshaw 1995), the joint roughness coefficient (JRC) (Barton et al. 1985), or the contact asperity ratio (Walsh 1981). However, recent experimental investigations imply that a stress-dependent anisotropic flow occurs in tensile fractures with displacement (Auradou et al. 2005). The permeability (i.e., the hydraulic aperture) in the direction parallel to the displacement can be three orders of magnitude smaller than that in the direction perpendicular to the displacement, at stresses up to $70 \mathrm{MPa}$ (Nemoto et al. (2009), as also supported by numerical studies (Thompson and Brown 1991; Méheust and Schmittbuhl 2001; Matsuki et al. 2006; Lang et al. 2018). Zimmerman et al. (1992) conclude that the permeability of a fracture not only depends on the size of the contact area but also on the shape of the propping asperities. The present direct observations on contact asperities show that a preferential orientation of the contact area (i.e., perpendicular to the shear displacement) is induced when the adjacent fracture walls are offset. However, this is less obvious as the displacement is increased (Fig. 11). In summary, without considering the aforementioned effects, the prediction of hydraulic aperture solely based on the average surface roughness, the mean aperture, or the contact area ratio would result in large uncertainties in comparison to the measured value, especially for fractures with a shear displacement.

\subsection{Fracture Roughness and Displacement-Related Fracture Aperture}

The fracture apertures with displacement are likely determined by the scale-dependent surface roughness. For sawcut fractures, where a roll-off region occurs, fracture aperture remains invariant when the offset $\delta$ is larger than $\lambda^{*}$ (Fig. 7a, b), which is consistent with the numerical analysis of the measured surface data (Fig. 8a). For tensile fractures, a drastic increase of fracture aperture occurs during the initiation of displacement until about 300-400 $\mu \mathrm{m}$ [regime (1) in Fig. 8a)], which is equal to the crossover wavelength $\lambda^{*}$ of these fractures (Sect. 3.2). This behavior is probably controlled by the intrinsic roughness at the grain scale (mostly intergranular fracturing, Fig. 16). Moreover, a further increase in displacement $\delta>\lambda^{*}$ yields slightly less increase in aperture [regime (2) in Fig. 8a] and a tendency of the mean aperture to converge is observed in regime (3). The former may be related to the self-affine invariance of the surface. The latter regime (convergence), however, considering a larger fracture size (e.g., $d m$ to $m$, rather than $\mathrm{cm}$ as in this study), may not exist unless a roll-off region occurs at some wavelength scale. 
(a)

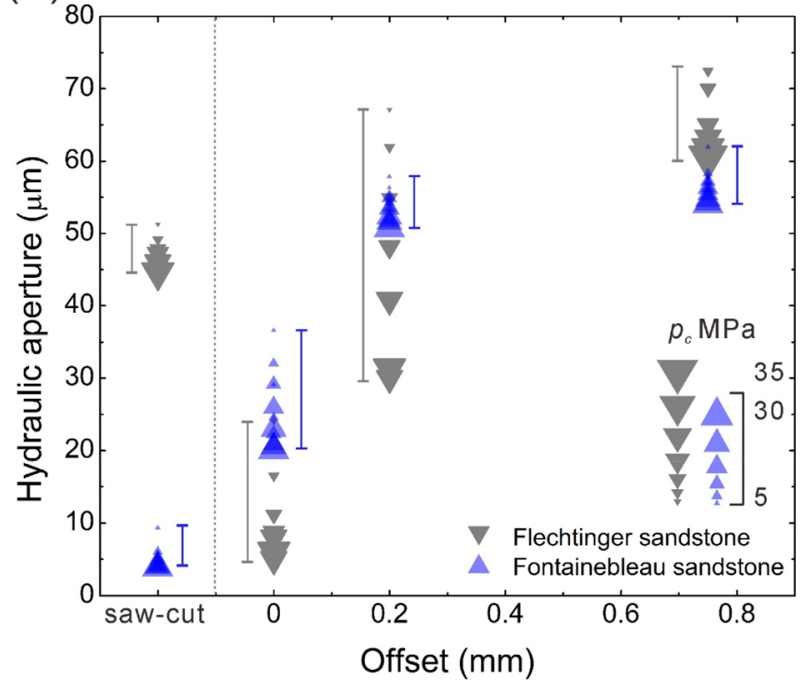

(b)

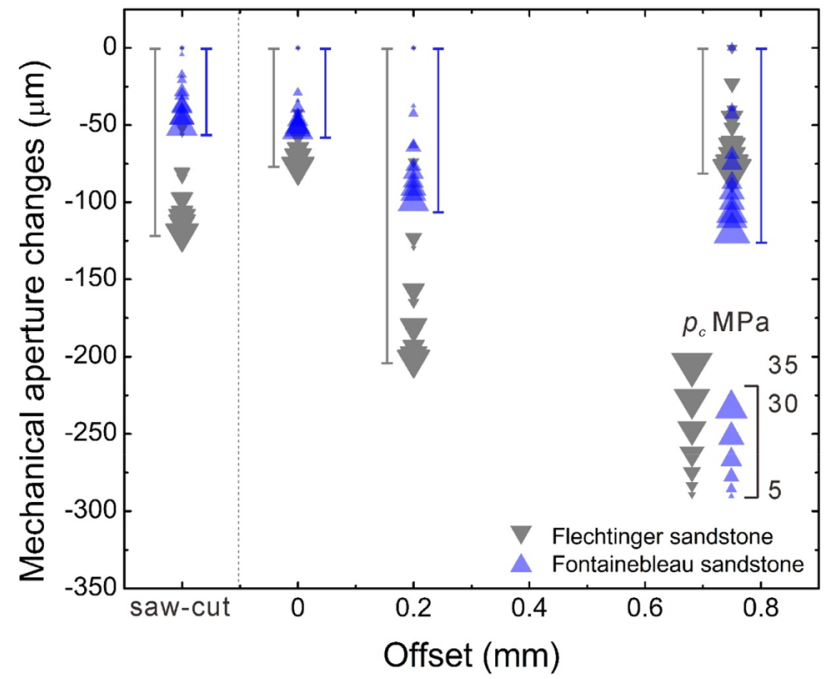

Fig. 15 Hydraulic aperture (a) and mechanical aperture changes (b) at the corresponding confining pressure as a function of the respective fracture wall offset

This scale-dependence issue commonly exists in laboratory studies due to the limitations of the sample size (Hofmann et al. 2016; Vogler et al. 2016; Crawford et al. 2017). However, for hydraulic fracturing induced fractures, which are in the scope of this study, and unlike faults, these are commonly not displaced by large amounts. A small offset may already sufficiently enhance the fracture transmissivity and thus larger displacements are not necessary for this purpose. Therefore, laboratory studies on core samples may provide a well-founded lower bound for fracture permeability.

\subsection{Aperture Changes with Effective Stress}

The initial contact area, the fracture surface roughness, and the strength of the asperities that are in contact are commonly considered as the factors that mainly determine the deformation of the fracture when subjected to normal tress variations (Bandis et al. 1983; Kling et al. 2018; Zou et al. 2019). Figure 15 shows the variation ranges of the hydraulic and mechanical apertures for all samples. Flechtinger samples yield consistently larger changes in comparison to the corresponding Fontainebleau samples at the same stress conditions. This likely results from the differences in the mechanical properties of the asperities because the initial contact area ratios and the initial fracture apertures of the different samples with the same offset are in about the same range (Table 3), although the fracture roughness varies slightly between samples (Table 2). Moreover, when the fracture walls are offset, both rock types maintain relatively high hydraulic aperture values in comparison to the aligned samples due to shear dilation. The trend of dilatancy likely follows the same behavior as obtained from the numerical calculations in Fig. 8a, where a drastic mechanical aperture increase occurs initially upon a one-two grain size offset and any further displacement then has progressively less effect. With ongoing brittle asperity failure during loading, the contact area ratio increases. The $\mu \mathrm{CT}$ results clearly demonstrate that the contact area ratios of the mismatched Flechtinger samples are significantly larger than those of the corresponding Fontainebleau samples after the experiments (Table 3), which indicates that more permanent damage has occurred in the Flechtinger samples (Fig. 17). However, an increase in fracture wall displacement leads to a noticeable reduction of the final contact area ratio in both rocks by increasing the mismatch of the adjacent fracture surfaces. The mechanical damage of the contact asperities only occurs locally, unless the adjacent fracture walls are aligned (see cross-section images of the sample ends after the experiments in Figs. 18, 19). It is noticed that the larger the initial mean aperture, the larger is the final aperture (Table 3). The smallest contact area ratio of $3.7 \%$ (FOF1) was sufficient to keep the fracture open at effective stresses up to $29 \mathrm{MPa}$. Overall, the contact area is determined, first, by the mismatch of the fracture walls and, second, by the strength of the asperities. Therefore, a stronger rock (i.e., Fontainebleau sandstone in the present case) displays a significantly smaller contact area ratio than a comparatively softer rock. 


\subsection{Implications}

Hydraulic fracturing in a tight reservoir formation to enhance its conductivity to fluid flow requires a preceding understanding of the target formation. Unlike randomly open fractures in granitic rocks, fractures generated in sedimentary formations might be largely affected by their intrinsic structure (e.g., bedding, anisotropy) that developed over geological time scales. The fracture surface roughness may be significantly different depending on the rock's individual microstructure. By analyzing the fracture surface roughness of an analog rock, one may estimate the maximum selfpropping potential upon fracture wall displacement based on the fracture surface information. By conducting laboratory flow-through experiments at varying normal stress, one can further estimate the sustainability of fracture permeability, which can be used as first-hand information to decide whether or not to use proppants in the target reservoir. For example, for a fracture surface roughness with a clear rolloff wavelength (Sect. 4.2), a shear displacement larger than this value would consequently have a rather limited effect on mechanical aperture. If the corresponding hydraulic aperture remains significantly small, in this case, proppants would be indispensable since self-propping of the fracture would not be sufficient to allow for substantial fluid flow. This circumstance may occur in anisotropic formations with welloriented bedding layers and fractures generated along the bedding planes.

At the long term, self-propping fractures undergo a fundamental change in surface roughness by the destruction of asperities induced either by plastic deformation or pressure solution. The fracture surface is thus permanently reshaped in a way to ultimately be flat. Hydraulic stimulation treatments in such pre-existing fractures would be less efficient in comparison to freshly generated ones. Under these circumstances, again, introducing proppants into the fracture would be very helpful. It is worth noting that the contact asperities have a preferential orientation that generally is perpendicular to the displacement (Durham and Bonner 1994; Méheust and Schmittbuhl 2001; Nemoto et al. 2009), which is more pronounced when the offset between the adjacent fracture surfaces is small (Sect. 3.4). Therefore, an increase of the displacement would not only increase the aperture but also decrease the flow anisotropy within the fracture.

\section{Conclusions}

In the present study, stress-dependent hydraulic and mechanical fracture aperture changes of displaced tensile fractures, aligned tensile fractures, and saw-cut fractures of two sandstones (i.e., Flechtinger and Fontainebleau) were experimentally investigated at cyclic confining pressures between 5 and $30 \mathrm{MPa}$. Fracture surface topographies were determined by white light interferometry and the spatial fracture configurations, including information on the contact asperities, were analyzed with X-ray microtomography.

It was found that a relative fracture wall displacement can significantly enhance fracture aperture both hydraulically and mechanically, but dependent on the fracture surface roughness. For saw-cut fractures, where a roll-off wavelength exists for the present sample size, the fracture surfaces remain scale-independent above this wavelength, where any increment of offset would not change the aperture. For tensile fractures, these are likely self-affine with a Hurst exponent of $0.54 \pm 0.04$ over a larger scale, and thus, fracture aperture is scale-dependent and is consequently increasing with an increase in offset unless a roll-off wavelength occurs. A comparison between the mechanical and hydraulic apertures showed that the mechanical apertures varied significantly more than the corresponding hydraulic apertures for all samples, as is also illustrated in the proposed conceptual model.

It was found that the contact area ratio (after a loading-unloading cycle) is inversely correlated with the displacement, resulting from, first, the surface roughness and, second, the strength of the asperities that are in contact. The contact areas, generally, are oriented in a preferential direction perpendicular to the displacement causing an anisotropy of fluid flow. This anisotropy is more pronounced for small fracture wall offsets.

This study demonstrates the effects of surface roughness, fracture wall offset, and mechanical rock properties on hydraulic and mechanical aperture variations. These factors do not operate independently but act coupled. Rough fractures, an induced fracture wall offset, and relatively strong fracture asperities are essential to keep a fracture sufficiently conductive for fluid flow at stressed conditions. As shown with this study, the self-propping potential of sedimentary rocks can be investigated using analog rock materials of contrasting 
mechanical properties to obtain information on how to better design hydraulic stimulation treatments of reservoir formations.

This study should stimulate a number of follow-up investigations with different focuses. Real-time in situ X-ray CT measurements permit monitoring of fracture closure with increasing stress and the evolution of mechanical aperture. Repeat measurements on samples with identically introduced fractures will disclose to what degree possible differences in surface microstructure affect the outcome of the present experiments for the different fracture types. Not least, a more detailed method comparison (i.e., between surface scanning, $\mu \mathrm{CT}$, and numerical approaches) to derive the mechanical aperture fields and the corresponding contact area ratios will prove valuable for method evaluation and improved relationships between hydraulic and mechanical apertures.

\section{Appendix: Images of the Fracture Microstructures}

See Figs. 16, 17, 18 and 19.

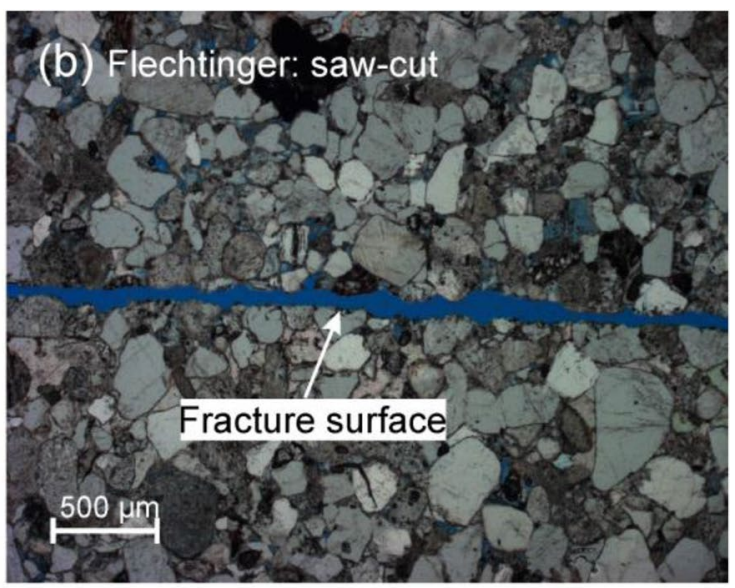

\section{Saw-cut samples: intragranular fracture}

Tensile samples: intergranular fracture (mainly)

$+$ intragranular fracture
Fig. 16 Thin section images of fractures in a saw-cut Fontainebleau sandstone, b saw-cut Flechtinger sandstone, and $\mathbf{c}$ tensile fractured Fontainebleau sandstone. Note that these representative fracture features were taken on other samples of the same respective rock type.
The tensile fractures in Flechtinger sandstone are mainly intergranular (see Fig. 18) due to its relatively low strength and weak cementation (Zang et al. 1996) 
Fig. 17 Images of fracture surfaces after the experiments. a Flechtinger samples and $\mathbf{b}$ Fontainebleau samples. Areas of microdamage can be identified in the displaced Flechtinger samples but show to be highly localized
Fig. 18 Images and sketches of the fracture void space taken on the Flechtinger sandstone sample ends after the experiments at dry and unconfined but jacketed conditions. a-d Samples FF1 through FF4 (a)
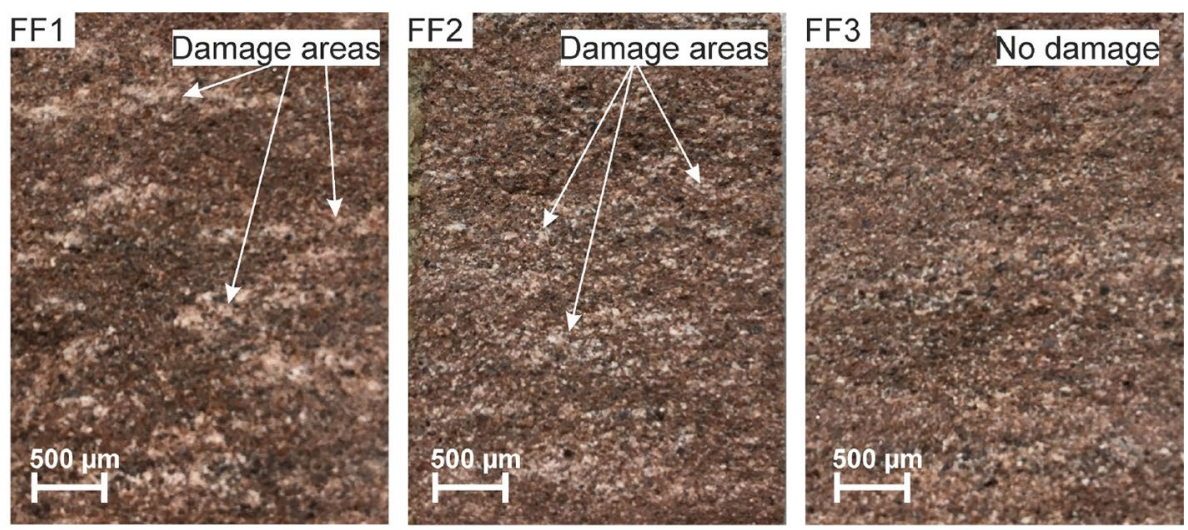

(b)
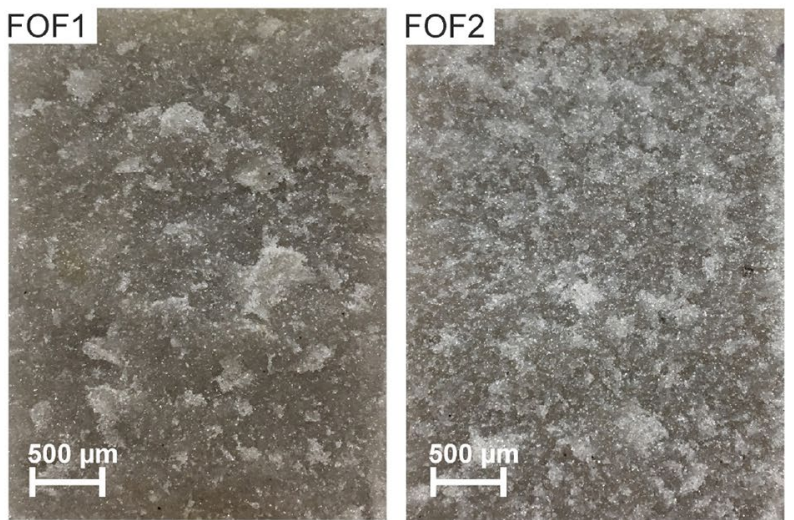

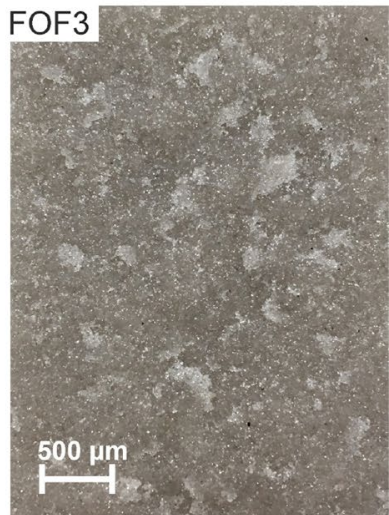

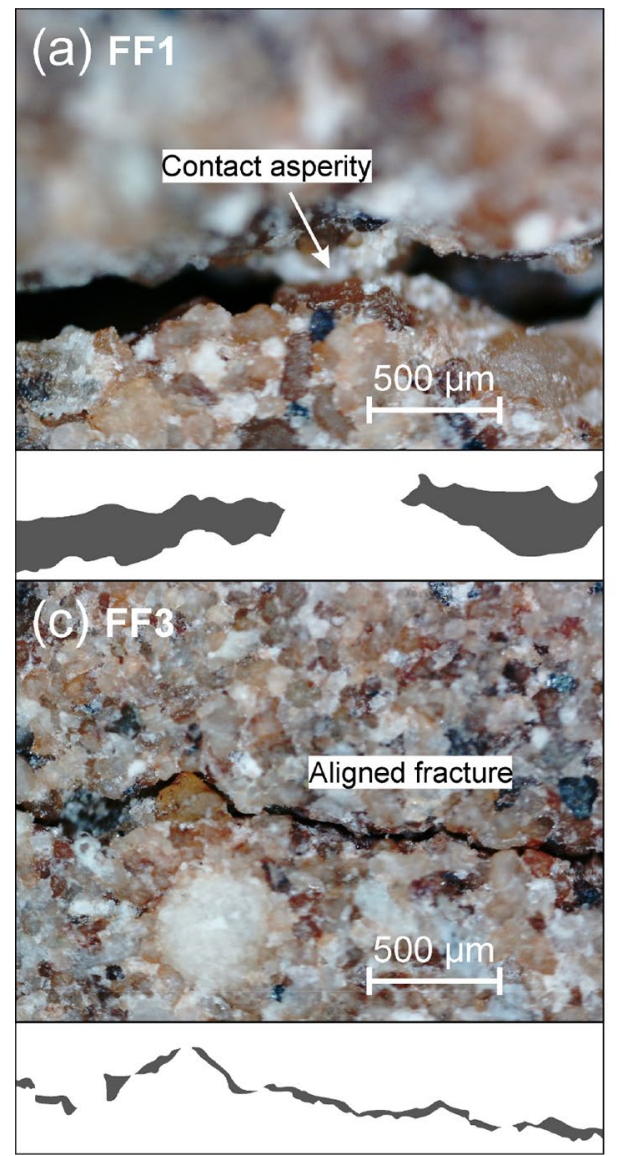

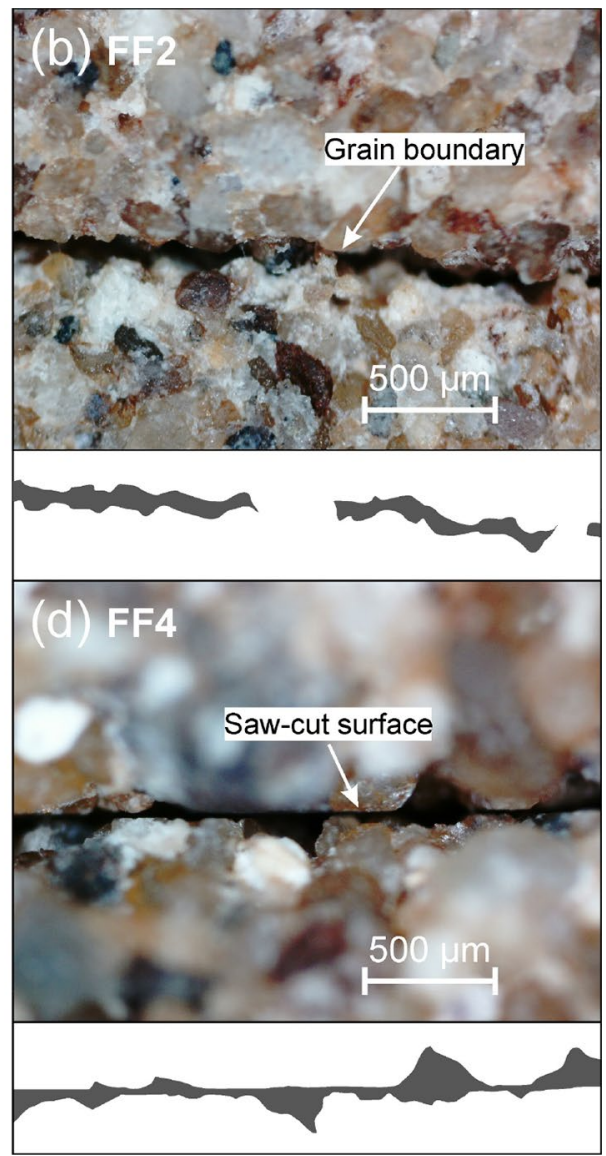


Fig. 19 Images and sketches of the fracture void space taken on the Fontainebleau sandstone sample ends after the experiments at dry and unconfined but jacketed conditions. a-d Samples FOF1 through FOF4
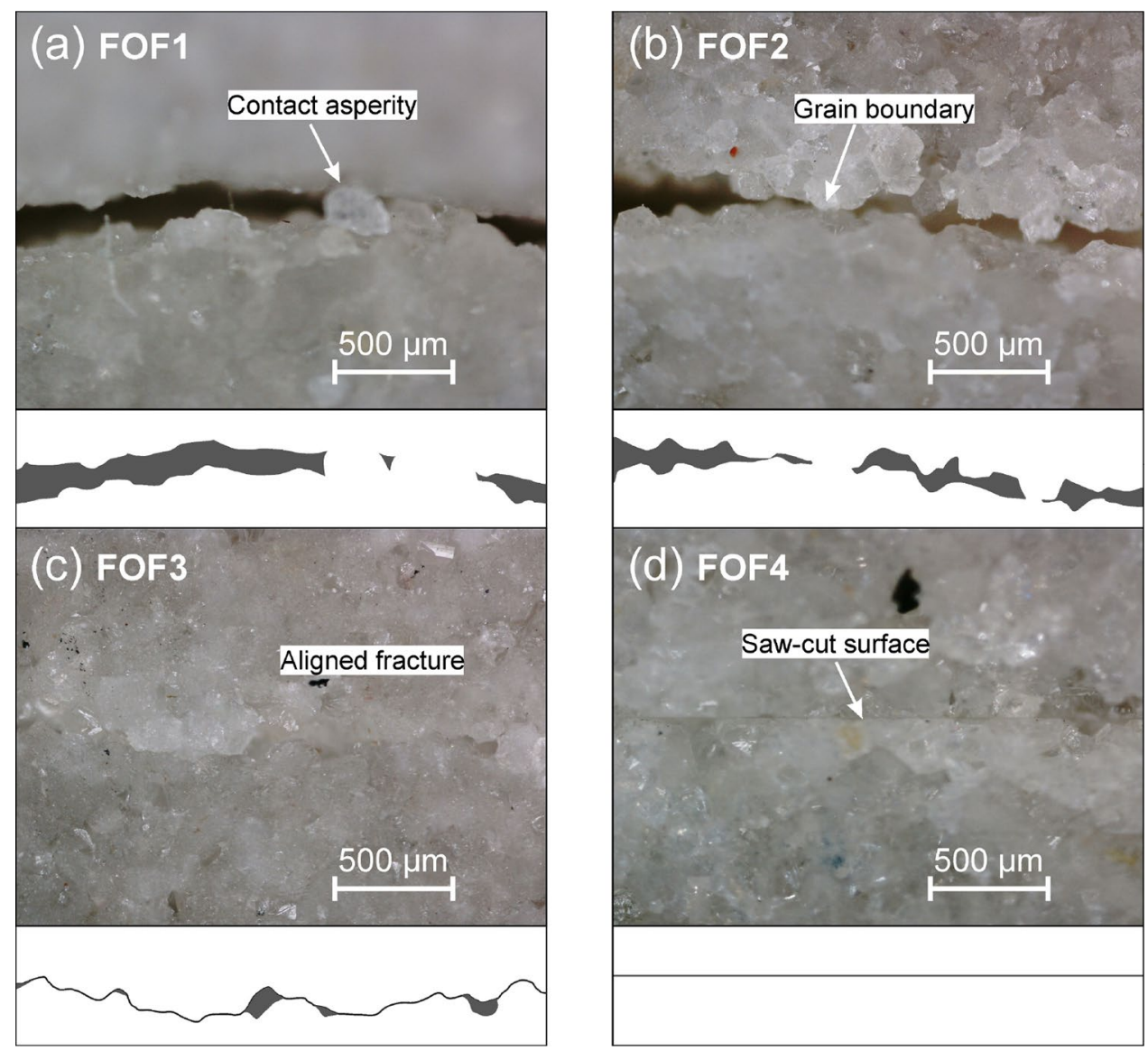

Acknowledgements The authors are grateful for constructive discussions with Prof. Michael Kühn (GFZ and University of Potsdam) and Prof. Christoph Hilgers (KIT). The authors also thank Erik Rybacki (GFZ) for his assistance with the X-ray $\mu \mathrm{CT}$ measurements, Michael Naumann (GFZ) for technical support with the sample preparation, Christian Kluge (GFZ) for help with the surface data analysis, and Dr. Hannes Hofmann (GFZ) for kindly sharing his experimental data of granitic rock fractures for comparison purposes. Chaojie Cheng thanks the China Scholarship Council (Grant No. 201606410056) for granting a fellowship to perform this study. This work was supported by the German Federal Ministry of Economic Affairs and Energy (BMWi) under grant No. 0324065 . The authors greatly acknowledge the constructive reviews of the associate editor and one anonymous reviewer that helped to improve the manuscript.

Funding Open Access funding enabled and organized by Projekt DEAL.

Open Access This article is licensed under a Creative Commons Attribution 4.0 International License, which permits use, sharing, adaptation, distribution and reproduction in any medium or format, as long as you give appropriate credit to the original author(s) and the source, provide a link to the Creative Commons licence, and indicate if changes were made. The images or other third party material in this article are included in the article's Creative Commons licence, unless indicated otherwise in a credit line to the material. If material is not included in the article's Creative Commons licence and your intended use is not permitted by statutory regulation or exceeds the permitted use, you will need to obtain permission directly from the copyright holder. To view a copy of this licence, visit http://creativecommons.org/licenses/by/4.0/.

\section{References}

Arns CH, Knackstedt MA, Pinczewski WV, Garboczi EJ (2002) Computation of linear elastic properties from microtomographic images: methodology and agreement between theory and experiment. Geophysics 67:1396-1405. https://doi.org/10.1190/1.15127 85

Auradou H, Drazer G, Hulin J-P, Koplik J (2005) Permeability anisotropy induced by the shear displacement of rough fracture walls. Water Resour Res 41:W09423. https://doi.org/10.1029/2005W R003938

Bandis SC, Lumsden AC, Barton NR (1983) Fundamentals of rock joint deformation. Int J Rock Mech Min Sci Geomech Abstr 20:249-268. https://doi.org/10.1016/0148-9062(83)90595-8

Barton N (1973) Review of a new shear-strength criterion for rock joints. Eng Geol 7:287-332. https://doi.org/10.1016/00137952(73)90013-6

Barton N, Bandis S, Bakhtar K (1985) Strength, deformation and conductivity coupling of rock joints. Int J Rock Mech Min Sci Geomech Abstr 22:121-140. https://doi.org/10.1016/01489062(85) $93227-9$

Baud P, Wong T-f, Zhu W (2014) Effects of porosity and crack density on the compressive strength of rocks. Int J Rock Mech Min Sci 67:202-211. https://doi.org/10.1016/j.ijrmms.2013.08.031 
Blöcher G, Reinsch T, Henninges J, Milsch H, Regenspurg S, Kummerow J et al (2016) Hydraulic history and current state of the deep geothermal reservoir Groß Schönebeck. Geothermics 63:27-43. https://doi.org/10.1016/j.geothermics.2015.07.008

Boffa J, Allain C (1998) Experimental analysis of fracture rugosity in granular and compact rocks. Eur Phys J Appl Phys 2:281-289. https://doi.org/10.1051/epjap:1998194

Brown SR, Scholz CH (1985) Closure of random elastic surfaces in contact. J Geophys Res 90:5531-5545. https://doi.org/10.1029/ JB090iB07p05531

Candela T, Renard F, Klinger Y, Mair K, Schmittbuhl J, Brodsky EE (2012) Roughness of fault surfaces over nine decades of length scales. J Geophys Res Solid Earth 117:B08409. https://doi.org/ 10.1029/2011JB009041

Chen Z, Narayan SP, Yang Z, Rahman SS (2000) An experimental investigation of hydraulic behaviour of fractures and joints in granitic rock. Int J Rock Mech Min Sci 37:1061-1071. https://doi. org/10.1016/S1365-1609(00)00039-3

Cosgrove J (1995) The expression of hydraulic fracturing in rocks and sediments. Geol Soc Lond Spec Publ 92:187-196. https://doi.org/ 10.1144/GSL.SP.1995.092.01.10

Crawford BR, Tsenn MC, Homburg JM, Stehle RC, Freysteinson JA, Reese WC (2017) Incorporating scale-dependent fracture stiffness for improved reservoir performance prediction. Rock Mech Rock Eng 50:3349-3359. https://doi.org/10.1007/s00603-017-1314-z

Darcy H (1856) Les fontaines publique de la ville de Dijon. Dalmont, Paris

Diaz M, Kim KY, Yeom S, Zhuang L, Park S, Min KB (2017) Surface roughness characterization of open and closed rock joints in deep cores using X-ray computed tomography. Int J Rock Mech Min Sci 98:10-19. https://doi.org/10.1016/j.ijrmms.2017.07.001

Durham WB, Bonner BP (1994) Self-propping and fluid flow in slightly offset joints at high effective pressures. J Geophys Res 99:9391-9399. https://doi.org/10.1029/94jb00242

Fang Y, Elsworth D, Ishibashi T, Zhang F (2018) Permeability evolution and frictional stability of fabricated fractures with specified roughness. J Geophys Res Solid Earth 123:9355-9375. https:// doi.org/10.1029/2018jb016215

Fischer C, Dunkl I, von Eynatten H, Wijbrans JR, Gaupp R (2012) Products and timing of diagenetic processes in Upper Rotliegend sandstones from Bebertal (North German Basin, Parchim Formation, Flechtingen High, Germany). Geol Mag 149:827-840. https://doi.org/10.1017/S0016756811001087

Ge S (1997) A governing equation for fluid flow in rough fractures. Water Resour Res 33:53-61. https://doi.org/10.1029/96WR02588

Hakami E, Larsson E (1996) Aperture measurements and flow experiments on a single natural fracture. Int J Rock Mech Min Sci 33:395-404. https://doi.org/10.1016/0148-9062(95)00070-4

Hassanzadegan A, Blöcher G, Zimmermann G, Milsch H (2012) Thermoporoelastic properties of Flechtinger sandstone. Int J Rock Mech Min Sci 49:94-104. https://doi.org/10.1016/j.ijrmms.2011. 11.002

Hassanzadegan A, Blöcher G, Milsch H, Urpi L, Zimmermann G (2013) The effects of temperature and pressure on the porosity evolution of Flechtinger sandstone. Rock Mech Rock Eng 47:421434. https://doi.org/10.1007/s00603-013-0401-z

Hofmann H, Blocher G, Milsch H, Babadagli T, Zimmermann G (2016) Transmissivity of aligned and displaced tensile fractures in granitic rocks during cyclic loading. Int J Rock Mech Min Sci 87:69-84. https://doi.org/10.1016/j.ijrmms.2016.05.011

Hofmann H, Zimmermann G, Farkas M, Huenges E, Zang A, Leonhardt M et al (2019) First field application of cyclic soft stimulation at the Pohang Enhanced Geothermal System site in Korea. Geophys J Int 217:926-949. https://doi.org/10.1093/gji/ggz058

Huang B, Liu J (2017) Experimental investigation of the effect of bedding planes on hydraulic fracturing under true triaxial stress.
Rock Mech Rock Eng 50:2627-2643. https://doi.org/10.1007/ s00603-017-1261-8

Kling T, Huo D, Schwarz JO, Enzmann F, Benson S, Blum P (2016) Simulating stress-dependent fluid flow in a fractured core sample using real-time X-ray CT data. Solid Earth 7:1109-1124. https:// doi.org/10.5194/se-7-1109-2016

Kling T, Vogler D, Pastewka L, Amann F, Blum P (2018) Numerical simulations and validation of contact mechanics in a granodiorite fracture. Rock Mech Rock Eng 51:2805-2824. https://doi. org/10.1007/s00603-018-1498-x

Kluge C, Blöcher G, Barnhoorn A, Schmittbuhl J, Bruhn D (2021) Permeability evolution during shear zone initiation in lowporosity rocks. Rock Mech Rock Eng. https://doi.org/10.1007/ s00603-020-02356-0

Konzuk JS, Kueper BH (2004) Evaluation of cubic law based models describing single-phase flow through a rough-walled fracture. Water Resour Res 40:W02402. https://doi.org/10.1029/2003W R002356

Kranzz R, Frankel A, Engelder T, Scholz C (1979) The permeability of whole and jointed Barre granite. Int J Rock Mech Min Sci Geomech Abstr 16:225-234. https://doi.org/10.1016/01489062(79)91197-5

Kushnir AR, Heap MJ, Baud P (2018) Assessing the role of fractures on the permeability of the Permo-Triassic sandstones at the Soultz-sous-Forêts (France) geothermal site. Geothermics 74:181-189. https://doi.org/10.1016/j.geothermics.2018.03.009

Lang PS, Paluszny A, Zimmerman RW (2015) Hydraulic sealing due to pressure solution contact zone growth in siliciclastic rock fractures. J Geophys Res Solid Earth 120:4080-4101. https:// doi.org/10.1002/2015JB011968

Lang PS, Paluszny A, Zimmerman RW (2016) Evolution of fracture normal stiffness due to pressure dissolution and precipitation. Int J Rock Mech Min Sci 88:12-22. https://doi.org/10.1016/j. ijrmms.2016.06.004

Lang PS, Paluszny A, Nejati M, Zimmerman RW (2018) Relationship between the orientation of maximum permeability and intermediate principal stress in fractured rocks. Water Resour Res 54:8734-8755. https://doi.org/10.1029/2018wr023189

Li D, Wong LNY (2013) The Brazilian disc test for rock mechanics applications: review and new insights. Rock Mech Rock Eng 46:269-287. https://doi.org/10.1007/s00603-012-0257-7

Li YR, Zhang YB (2015) Quantitative estimation of joint roughness coefficient using statistical parameters. Int J Rock Mech Min Sci 77:27-35. https://doi.org/10.1016/j.jirmms.2015.03.016

Li B, Zhao Z, Jiang Y, Jing L (2015) Contact mechanism of a rock fracture subjected to normal loading and its impact on fast closure behavior during initial stage of fluid flow experiment. Int $\mathbf{J}$ Numer Anal Methods Geomech 39:1431-1449. https://doi.org/ 10.1002/nag. 2365

Matsuki K, Chida Y, Sakaguchi K, Glover P (2006) Size effect on aperture and permeability of a fracture as estimated in large synthetic fractures. Int J Rock Mech Min Sci 43:726-755. https://doi.org/ 10.1016/j.ijrmms.2005.12.001

Méheust Y, Schmittbuhl J (2001) Geometrical heterogeneities and permeability anisotropy of rough fractures. J Geophys Res 106:20892102. https://doi.org/10.1029/2000JB900306

Milsch H, Spangenberg E, Kulenkampff J, Meyhöfer S (2008) A new apparatus for long-term petrophysical investigations on geothermal reservoir rocks at simulated in-situ conditions. Transp Porous Med 74:73-85. https://doi.org/10.1007/s11242-007-9186-4

Milsch H, Hofmann H, Blocher G (2016) An experimental and numerical evaluation of continuous fracture permeability measurements during effective pressure cycles. Int J Rock Mech Min Sci 89:109_ 115. https://doi.org/10.1016/j.ijrmms.2016.09.002 
Mourzenko VV, Thovert J-F, Adler PM (1995) Permeability of a single fracture; validity of the Reynolds equation. J Phys II 5:465-482. https://doi.org/10.1051/jp2:1995133

Nemoto K, Watanabe N, Hirano N, Tsuchiya N (2009) Direct measurement of contact area and stress dependence of anisotropic flow through rock fracture with heterogeneous aperture distribution. Earth Planet Sci Lett 281:81-87. https://doi.org/10.1016/j.epsl. 2009.02.005

Neuville A, Toussaint R, Schmittbuhl J (2012) Fracture aperture reconstruction and determination of hydrological properties: a case study at Draix (French Alps). Hydrol Process 26:2095-2105. https://doi.org/10.1002/hyp.7985

Persson BN, Albohr O, Tartaglino U, Volokitin A, Tosatti E (2004) On the nature of surface roughness with application to contact mechanics, sealing, rubber friction and adhesion. J Phys Condens Matter 17:R1-R62. https://doi.org/10.1088/0953-8984/17/1/R01

Plouraboué F, Kurowski P, Hulin J-P, Roux S, Schmittbuhl J (1995) Aperture of rough cracks. Phys Rev E 51:1675. https://doi.org/10. 1103/PhysRevE.51.1675

Ponson L, Auradou H, Pessel M, Lazarus V, Hulin J-P (2007) Failure mechanisms and surface roughness statistics of fractured Fontainebleau sandstone. Phys Rev E. https://doi.org/10.1103/PhysR evE.76.036108

Raven K, Gale J (1985) Water flow in a natural rock fracture as a function of stress and sample size. Int J Rock Mech Min Sci Geomech Abstr 22:251-261. https://doi.org/10.1016/0148-9062(85)92952-3

Renard F, Bernard D, Desrues J, Ougier-Simonin A (2009) 3D imaging of fracture propagation using synchrotron X-ray microtomography. Earth Planet Sci Lett 286:285-291. https://doi.org/10.1016/j. eps1.2009.06.040

Renard F, Beauprêtre S, Voisin C, Zigone D, Candela T, Dysthe DK, Gratier J-P (2012) Strength evolution of a reactive frictional interface is controlled by the dynamics of contacts and chemical effects. Earth Planet Sci Lett 341-344:20-34. https://doi.org/10. 1016/j.epsl.2012.04.048

Renshaw CE (1995) On the relationship between mechanical and hydraulic apertures in rough-walled fractures. J Geophys Res 100:24629-24636. https://doi.org/10.1029/95JB02159

Rutqvist J (2015) Fractured rock stress-permeability relationships from in situ data and effects of temperature and chemicalmechanical couplings. Geofluids 15:48-66. https://doi.org/10. 1111/gfl.12089

Saadi FA, Wolf K-H, Cv K (2017) Characterization of Fontainebleau sandstone: quartz overgrowth and its impact on pore-throat framework. J Pet Environ Biotechnol 08:1-12. https://doi.org/10.4172/ 2157-7463.1000328

Sausse J (2002) Hydromechanical properties and alteration of natural fracture surfaces in the Soultz granite (Bas-Rhin, France). Tectonophysics 348:169-185. https://doi.org/10.1016/S00401951(01)00255-4

Schepers A, Milsch H (2013) Relationships between fluid-rock interactions and the electrical conductivity of sandstones. J Geophys Res Solid Earth 118:3304-3317. https://doi.org/10.1002/jgrb.50241

Schmittbuhl J, Renard F, Gratier J-P, Toussaint R (2004) Roughness of stylolites: implications of 3D high resolution topography measurements. Phys Rev Lett 93:238501-238504. https://doi.org/10.1103/ PhysRevLett.93.238501

Schmittbuhl J, Steyer A, Jouniaux L, Toussaint R (2008) Fracture morphology and viscous transport. Int J Rock Mech Min Sci 45:422430. https://doi.org/10.1016/j.ijrmms.2007.07.007

Schneider CA, Rasband WS, Eliceiri KW (2012) NIH Image to ImageJ: 25 years of image analysis. Nat Methods 9:671-675. https://doi. org/10.1038/nmeth.2089
Singh KK, Singh D, Ranjith P (2015) Laboratory simulation of flow through single fractured granite. Rock Mech Rock Eng 48:9871000. https://doi.org/10.1007/s00603-014-0630-9

Thompson ME, Brown SR (1991) The effect of anisotropic surface roughness on flow and transport in fractures. J Geophys Res Solid Earth 96:21923-21932. https://doi.org/10.1029/91jb02252

Tse R, Cruden D (1979) Estimating joint roughness coefficients. Int J Rock Mech Min Sci Geomech Abstr 16:303-307. https://doi.org/ 10.1016/0148-9062(79)90241-9

Vogler D, Amann F, Bayer P, Elsworth D (2016) Permeability evolution in natural fractures subject to cyclic loading and gouge formation. Rock Mech Rock Eng 49:3463-3479. https://doi.org/ 10.1007/s00603-016-1022-0

Vogler D, Settgast RR, Annavarapu C, Madonna C, Bayer P, Amann F (2018) Experiments and simulations of fully hydro-mechanically coupled response of rough fractures exposed to high-pressure fluid injection. J Geophys Res-Solid Earth 123:1186-1200. https://doi. org/10.1002/2017JB015057

Walsh J (1981) Effect of pore pressure and confining pressure on fracture permeability. Int J Rock Mech Min Sci Geomech Abstr 18:429-435. https://doi.org/10.1016/0148-9062(81)90006-1

Watanabe N, Hirano N, Tsuchiya N (2008) Determination of aperture structure and fluid flow in a rock fracture by high-resolution numerical modeling on the basis of a flow-through experiment under confining pressure. Water Resour Res 44:W06412. https:// doi.org/10.1029/2006wr005411

Witherspoon PA, Wang JS, Iwai K, Gale JE (1980) Validity of cubic law for fluid flow in a deformable rock fracture. Water Resour Res 16:1016-1024. https://doi.org/10.1029/WR016i006p01016

Zang A, Wagner CF, Dresen G (1996) Acoustic emission, microstructure, and damage model of dry and wet sandstone stressed to failure. J Geophys Res Solid Earth 101:17507-17521. https://doi.org/ 10.1029/96JB01189

Zhuang L, Jung SG, Diaz M, Kim KY, Hofmann H, Min K-B et al (2020) Laboratory true triaxial hydraulic fracturing of granite under six fluid injection schemes and grain-scale fracture observations. Rock Mech Rock Eng 53:4329-4344. https://doi.org/10. 1007/s00603-020-02170-8

Zimmerman RW, Bodvarsson GS (1996) Hydraulic conductivity of rock fractures. Transp Porous Med 23:1-30. https://doi.org/10. 1007/BF00145263

Zimmerman RW, Kumar S, Bodvarsson GS (1991) Lubrication theory analysis of the permeability of rough-walled fractures. Int J Rock Mech Min Sci Geomech Abstr 28:325-331. https://doi.org/10. 1016/0148-9062(91)90597-F

Zimmerman RW, Chen D-W, Cook NG (1992) The effect of contact area on the permeability of fractures. J Hydrol 139:79-96. https:// doi.org/10.1016/0022-1694(92)90196-3

Zimmermann G, Zang A, Stephansson O, Klee G, Semiková H (2018) Permeability enhancement and fracture development of hydraulic In situ experiments in the Äspö Hard Rock Laboratory, Sweden. Rock Mech Rock Eng 52:495-515. https://doi.org/10.1007/ s00603-018-1499-9

Zou L, Li B, Mo Y, Cvetkovic V (2019) A high-resolution contact analysis of rough-walled crystalline rock fractures subject to normal stress. Rock Mech Rock Eng 53:2141-2155. https://doi.org/ 10.1007/s00603-019-02034-w

Publisher's Note Springer Nature remains neutral with regard to jurisdictional claims in published maps and institutional affiliations. 